\title{
Failure Analysis of PHILOS Plate Construct Used for Pantalar Arthrodesis Paper II-Screws and FEM Simulations
}

\author{
Farah Hamandi ${ }^{1}$ (), Richard Laughlin ${ }^{2}$ and Tarun Goswami ${ }^{1, *}$ \\ 1 Department of Biomedical, Industrial, and Human Factors Engineering, Wright State University, Dayton, \\ OH 45435, USA; hamandi.3@wright.edu \\ 2 Department of Orthopedic Surgery, Sports Medicine and Rehabilitation, Wright State University, Dayton, \\ $\mathrm{OH}$ 45435, USA; rtlaughlin@premierhealth.com \\ * Correspondence: tarun.goswami@wright.edu; Tel.: +1-937-775-5120
}

Received: 19 March 2018; Accepted: 16 April 2018; Published: 18 April 2018

check for updates

\begin{abstract}
A fractured stainless steel $3.5 \mathrm{~mm}$ proximal humerus internal locking system (PHILOS) plate and screws were investigated in this paper. This plate was used for ankle arthrodesis of a 68-year-old female with a right ankle deformity. Both the plate and screws were considered in this investigation. Optical and scanning electron microscopes (SEM) were used to document fracture surface characteristics, such as extensive scratching, plastic deformation, rubbed surfaces, discoloration, and pitting, along with cleavage, secondary cracking, deposits of debris, striations, and dimples. Indications of these features show that the plate failed by corrosion fatigue, however, overloading separated the screw(s) in two parts. Radiographic evidence shows that the screws failed ahead of the plate from the proximal end. Three-dimensional models of the plate and the screws: cortical, locking, and cannulated, were constructed using Solidworks and imported in ANSYS Workbench 16.2 to simulate the loading conditions and regions of stress development. Statistical analysis was conducted to understand the impact of different factors on the maximum von Mises stresses of the locking compression plate. These factors were the load, screw design pattern, coefficient of friction between the plate and screws, and cortical screw displacement. In summary, the finite element simulation of the plate validates the fractographic examination results. The following observations were made: (a) as the angle between the screws and the plates increased, the von Mises stresses increased in the cortical screws; and (b) the stress in the locking screws was lower than that of the cortical screws, which may be due to locking the screws with fixed angles onto the plate. Finally, fractographic examination of the cortical and locking screws supports the mechanism of corrosion-fatigue fracture from crack initiation sites, pits, due to the presence of inclusion bodies for this material (ASTM standards F138-03 and F139-03) documented for the plate in Paper I.
\end{abstract}

Keywords: locking plate; fracture; finite element; implant; cortical screw; locking screw

\section{Introduction}

Numerous methods of fixation have been advocated for tibiotalocalcaneal (TTC) arthrodesis, including external fixation, screws [1], intramedullary nails [2], dynamic compression plate fixation [3], and the use of locking plates. Intramedullary nails have several advantages over other internal fixation devices, for instance, better bending and torsion strength [4,5]. However, this type of fixation may not be used with severe-deformity patients [6]. Plates are widely used in bone internal fixation. Different materials are used for medical implants, such as Ti-6Al-4V, 3161 stainless steel, Co Cr. 316L stainless steel is used extensively in internal fixation devices due to its excellent properties, such as its 
competitive price point and compatibility with the human body. On the other hand, corrosion fatigue can drastically affect the lifetime of the internal fixation devices and lead to catastrophic failure.

As screw positioning is one of the main problems that leads to the failure of plates, locking compression plates (LCP) are preferred in arthrodesis. With this technique, the screw head threads are fixed to the plate with a specific angle that helps in reducing the risk of screw failure. Locking screws increase the stabilization of fractures, but they are more expensive than other types of screws. Hybrid fixation uses a combination of both locking and non-locking screws, which improve the stabilization economically. The locking and hybrid construct principles are outlined in Goswami et al. [7].

\subsection{Bone Screw Aspects of Design}

A screw comprises of a head, shaft, thread, and tip.

- The screw heads can be crossed, hexagonal, or star. The crossed screw head driver has a good advantage in torque transmission [8]. However, a hexagonal driver provides a strong and insensitive alignment connection with the screw.

- The screw shaft represents a smooth link with no threads and might be (1) fully threaded with the cross-sectional diameter decreasing from the head to the bottom tip of the screw; (2) has a similar diameter for both the shaft and the thread root and provides strength and alignment inside the holes, however, it may require over drilling during surgery; and (3) have a similar diameter for both the shaft and the thread major diameter, however, with a weaker shaft [9].

- Screw threads with a constant angle increase the depth and pitch of the screw, while decreasing the pitch of the screw decreases the depth but keeps the angle constant. The surface of the thread should be perpendicular to the pullout load direction [9].

- The screw tip can be cork, blunt, self-tapping, or self-cutting. A self-tapping tip has a sharp flue that needs a lower amount of force. However, it needs $30-40 \%$ more torque to be placed [9].

\subsection{Biomechanics of Bone Screws}

There are many differences among the cortical, cancellous, locking, and cannulated screws. The head of the locking screw has threads. Additionally, the size, core, and pitch of the threads change depending on the type of the screw. The cancellous screw has a larger pitch and a larger core diameter than the cortical screw. In addition, the tip of the screw is either rounded or fluted [10].

When using non-locking screws, a compressive force between the plate and the bone occurs with enough friction to provide the stability with a higher stress than the locking screws. On the other hand, the initial stress develops due to the tightening of the head inside the plate, followed by a compressive force that occurs on the bone around the locking screw. Additionally, the angle does not change between the locking screw and the plate that provides higher resistance against bending [11]. The cannulated screw has less strength than the non-cannulated screw as it has a larger core diameter [12]. The main mechanisms for screw failure are the excessive torque that leads to shear failure or the loading of the plate in a different direction than the screw, which leads to bending failure [9].

Studies showed that $42 \%$ of the torque that is applied to the screw is lost to overcoming the friction between the screw and the bone $[9,13]$. This is one of the main reasons that surgeons apply high force and torque, which leads to higher shear stress on the screw, where the shear stress is directly proportional to the torque and inversely proportional to the diameter. Shear failure force is proportional to the material ultimate shear stress and the thread shear area [14].

In addition, there are two main factors that affect the amount of torque required for the insertion of the screw, which are the tapping and lubrication. Perren [8] showed that $43 \%$ of torque loss happens due to the screw-plate friction, $42 \%$ of torque loss due to the screw threads-bone friction, and only $15 \%$ of torque transforms into an axial force. While, Hughes and Jordan [13] showed that $50 \%$ of torque occurred due to the screw-plate and screw-bone friction, $10 \%$ of torque loss is due to the screw 
threads-bone friction, $35 \%$ of torque loss is due to cutting threads, and only $5 \%$ of torque transforms into an axial force. In contrast, the lubricated and tapped screw friction decreased by $50 \%, 0 \%$ of torque loss is due to the screw threads cutting, and 65\% of torque transformed into axial force [9].

There are many designs of plates that can be used for tibiotalocalcaneal fixation or the fixation of a tibial bone fracture. Unfortunately, the lack of resources makes the best fixation option not always available. This issue has resulted in the use of humeral fixation plates for tibiotalocalcaneal arthrodesis. There are several studies that focused on the capability of using the humeral locking plate for tibiotalocalcaneal arthrodesis, as shown in Table 1, wherein 2007, a study on 18 patients showed that $94.4 \%$ of the patients had successful fusion after approximately 20 weeks when the proximal humeral locking plates were used for obtaining tibiotalocalcaneal arthrodesis [1]. Additionally, another study in 2011 reported successful results when the same plate was used for ankle arthrodesis [15]. In addition, in 2016 , Shearman et al. showed that $81 \%$ of patients had satisfactory results when proximal locking plates were used for obtaining tibiotalocalcaneal arthrodesis [4].

Table 1. Studies focused on the capability of proximal humerus internal locking system (PHILOS) for tibiotalocalcaneal arthrodesis.

\begin{tabular}{|c|c|c|c|c|c|}
\hline Authors & Year & Title & Age & $\begin{array}{c}\text { Gender } \\
\text { Male:Female }\end{array}$ & Details \\
\hline $\begin{array}{l}\text { Ahmad, J., Pour, A.E., } \\
\text { and Raikin, S.M. [1] }\end{array}$ & 2007 & $\begin{array}{l}\text { The modified use of a } \\
\text { proximal humeral } \\
\text { locking plate for } \\
\text { tibiotalocalcaneal } \\
\text { arthrodesis }\end{array}$ & $\begin{array}{l}\text { 22-72 years } \\
\text { Mean: } 54.2\end{array}$ & $11: 6$ & $\begin{array}{l}18 \text { patients showed that } 94.4 \% \\
\text { (17 of } 18) \text { of the patients had } \\
\text { successful fusion after } \\
\text { approximately } 20 \text { weeks when } \\
\text { the proximal humeral locking } \\
\text { plates were used for obtaining } \\
\text { tibiotalocalcaneal arthrodesis. }\end{array}$ \\
\hline $\begin{array}{c}\text { Shi, Z., Zhang, C., } \\
\text { Gu, W., Zhang, C., and } \\
\text { Zeng, B. [15] }\end{array}$ & 2011 & $\begin{array}{l}\text { Ankle arthrodesis by } \\
\text { lateral malleolus } \\
\text { osteotomy and internal } \\
\text { fixation with locking } \\
\text { proximal humeral plate }\end{array}$ & $\begin{array}{l}\text { 36-67 years } \\
\text { Mean: } 48\end{array}$ & $10: 8$ & $\begin{array}{l}\text { Reported successful results } \\
\text { when the same plate was used } \\
\text { for ankle arthrodesis. }\end{array}$ \\
\hline $\begin{array}{l}\text { Haider Twaij and } \\
\text { Dev Damany }\end{array}$ & 2013 & $\begin{array}{l}\text { PHILOS humerus plate } \\
\text { for a distal tibial fracture }\end{array}$ & 51 & 1:0 & A successful result for the case. \\
\hline
\end{tabular}

In the present study, a failed PHILOS construct was examined and a computational simulation performed to validate the regions of stress development causing the physical failure of the system.

\section{Background}

A fractured stainless steel $3.5 \mathrm{~mm}$ LCP proximal humerus locking plate (PHILOS), originally manufactured by Synthes, is investigated for the failure mechanism(s) responsible for its failure. A typical LCP proximal humerus locking plate is shown in Figure 1. It can be seen that the plate was inverted to handle the anatomical shape of the tibiotalocalcaneal area, where the proximal part of the plate was fixed to the calcaneus and talus. The fractured pieces are analyzed to determine the mechanism of failure. In Paper I, the PHILOS plate failure analysis was carried out and a state of the art literature review of hybrid constructs is summarized [16]. This paper not only presents the results of finite element simulations of the PHILOS construct (plate and screws) but also examines the failure mechanisms of the screws that failed. 

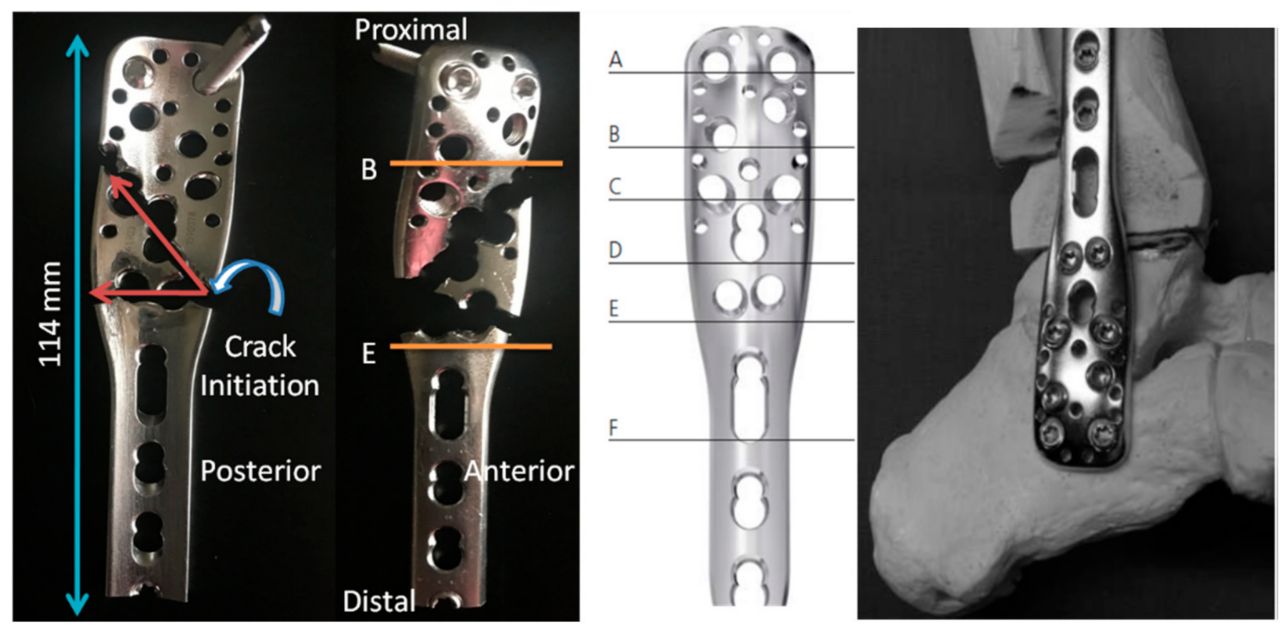

Figure 1. The fractured $3.5 \mathrm{~mm}$ LCP proximal humerus locking plate shaft showing the crack initiation and propagation in two directions (red arrows) (left). The proximal part of the plate is divided into six levels, from A to $\mathrm{F}$ (middle). It can be seen that the plate is inverted to align with the anatomical shape of the tibiotalocalcaneal area, where the proximal part of the plate was fixed to the calcaneus and talus (right).

The PHILOS plate and screws were used for a 68-year-old patient that had a right ankle plantar arthrodesis, deformation on the right ankle, and dislocation on the lateral subtalar joint. The distal part of the plate was fixed to the lateral part of tibia and calcaneus by $3.5 \mathrm{~mm}$ cortical screws. Additionally, $3.5 \mathrm{~mm}$ locking screws were used to fix the proximal part of the plate. Furthermore, a $6.5 \mathrm{~mm}$ cannulated screw was used to apply compression on tibiotalar and subtalar joints. In addition, $3.5 \mathrm{~mm}$ screws with washers were used to support the fusion of the talonavicular joint. After six years, the plate and the screws were removed from the body. Table 2 summarizes all the parts that are submitted for investigation.

Table 2. Pieces of the PHILOS system submitted for investigation.

\begin{tabular}{cccccc}
\hline Name of Device & Size & Company & Serial No. & Date of Insertion & Failure First Noticed \\
\hline LCP Proximal Humerus & $3.5 \mathrm{~mm}$ & DePuy Synthes & N/A & $08 / 2008$ & 2014 \\
Locking Plate & $3.5 \mathrm{~mm}$ & DePuy Synthes & N/A & $08 / 2008$ & $2010-2014$ \\
Cortical Screws & $3.5 \mathrm{~mm}$ & DePuy Synthes & N/A & $08 / 2008$ & $2011-2014$ \\
Locking Screws & $6.5 \mathrm{~mm}$ & Zimmer & N/A & $08 / 2008$ & 2013 \\
Cannulated Screw & N & Dimm & \\
\hline
\end{tabular}

Note: X-ray images with respect to dates are shown in [16].

\section{Visual Examination}

\subsection{The Plate}

Visual examination demonstrated that the LCP plate was fractured into three pieces. The anterior and posterior views of the plate are shown in Figure 1. The proximal part of the plate can be divided into six levels, from A to F [17], as shown in Figure 1.

The plate failed at levels B-E. Additionally, Figure 1 shows that the crack initiated from under one of the locking holes near the middle of the plate at level (E). This fracture progressed in two directions (the red arrows), one in the diagonal direction and another in the perpendicular direction, which caused the plate to fail into three pieces. The distal part of the plate shaft had been removed to perform some additional tests. Observing the plate under the optical microscopy showed a considerable amount of scratches and pitting. Details of the plate failure have been discussed in Paper I [16]. 


\subsection{The Screws}

Twelve screws were submitted for examination, as shown Figure 2. Four were $3.5 \mathrm{~mm}$ cortical non-locking screws, and three $(75 \%)$ of these screws fractured into two pieces. The X-ray images showed that the first cortical screw failed after two years of implantation [16] and the other two screws failed after five to six years [16], visible in X-rays. One of the cortical screw heads remained on the plate after removal. Seven $3.5 \mathrm{~mm}$ locking screws were submitted for investigation, and three $(42.8 \%)$ of these screws fractured into two pieces. It was difficult to visualize the time of failure of the locking screws after the implantation in the X-ray images because the screw density was high at the area of insertion of the locking screws. One of the locking screw heads and other undamaged locking screws remained in the plate after removal. In addition, one $6.5 \mathrm{~mm}$ cannulated screw fractured within five years of implantation, as was observed in the X-ray images [16]. No physical damage to the devices that may have led to the failure was observed. Radiographic evidence, as seen in Figure 1, shows that the screws failed ahead of the plate from the proximal end.

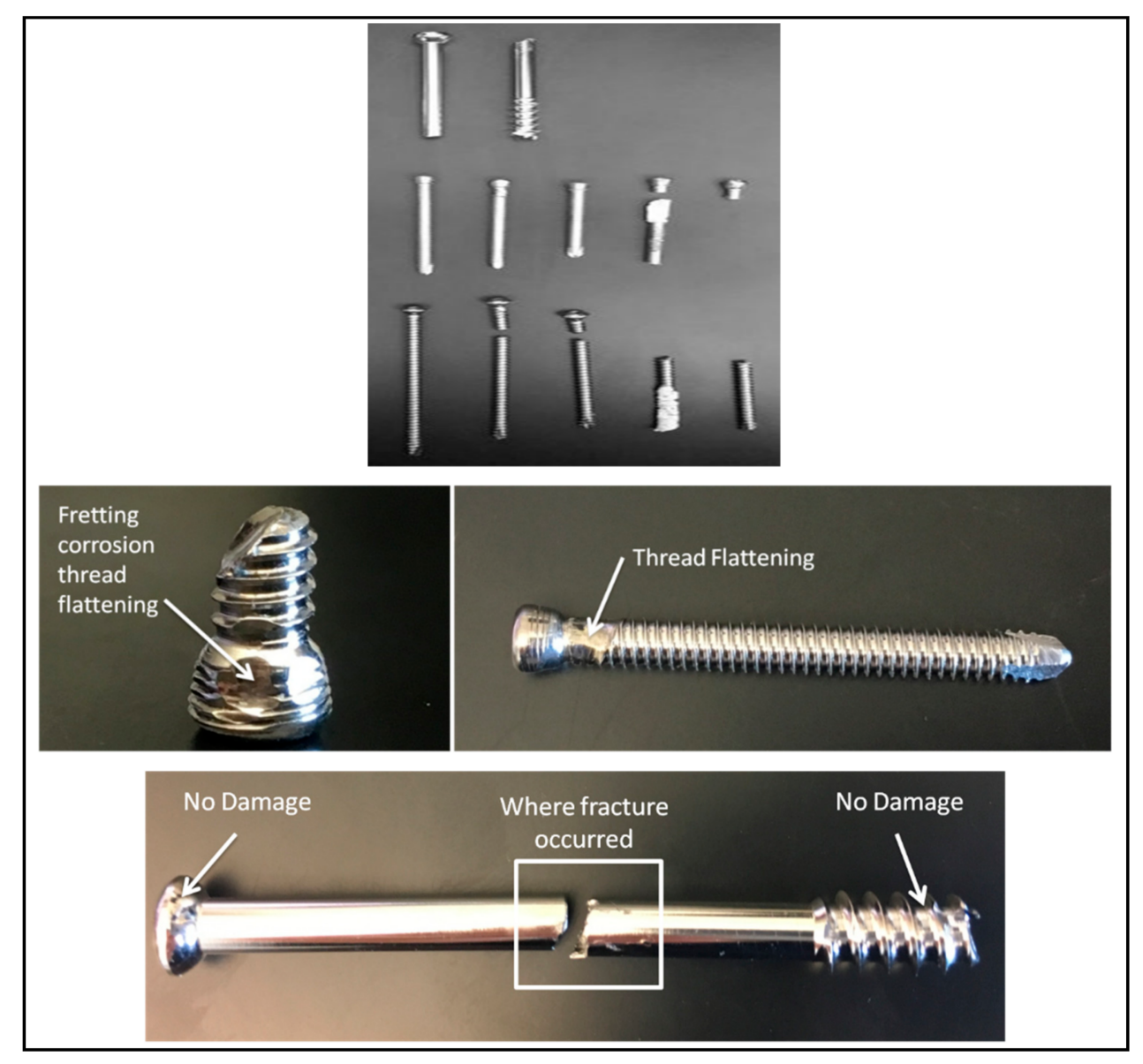

Figure 2. Screw visual observation showed the fractured screws (upper), some thread flattening (middle), and the fractured $6.5 \mathrm{~mm}$ cannulated screw (below).

\section{Fractographic Examination}

Optical and scanning electron microscopes were used to document the fracture surface characteristics such as extensive scratching, plastic deformation, rubbed surfaces, discoloration, and pitting, along with cleavage, cracking, deposits of debris, striations, and dimples. A PEMTRON scanning electron microscope (SEM PS-230, Seoul, Korea) with $10 \mathrm{KV}$ was used to perform the fractographic examination. Fractographic analysis was performed on the plate and four screws in the fractured regions. By examining the fractured surface of the plate, quasi-cleavage fracture was 
observed, as shown in Appendix A (Figure A1). The literature showed similar observations that the corrosion-fatigue mechanism was responsible for the failure of the plates [18-20]. However, another study showed that the failure of plates could be a result of improper material [21].

The cortical screws were marked as CS1, CS2, CS3, and CS4 from the proximal to the distal direction. The locking screws were marked depending on the level of insertion, shown in Figure 1, as LA, LB, LC, LD, and LE. Cortical screws CS1 and CS4 were examined with the SEM. Appendix A (Figures A2-A4) show the main details in CS1, where the presence of striations and microcracks can be noticed, while Appendix A (Figures A5-A7) shows the main details in CS4, where the presence of striations in different directions can be noticed. In addition, two locking screws were examined with the SEM. Appendix A (Figures A8-A11) shows the main details for the locking screws.

It can be noticed that the fractured surfaces of the screws were rubbed. Rubbing happened inside the body as the devices failed after two years of insertion and were kept inside the body for four more years, which caused the loss of some of the important features that caused the crack initiation. Additionally, it was observed that the cracks in the fatigue areas of the plate initiated from corrosion pits. In general, the investigation showed that the failure was a result of conjoint bending/torsion loading and corrosion-fatigue cracking that propagated from the bottom of pit(s). The pitting susceptibility of this material is widely documented in the literature arising from inclusions, which were reported in Paper I [16]. The mechanisms governing failure of the screws are similar to that found for the plate [16].

\section{Material Conformity}

The metallographic qualitative analysis was performed based on ASTM standards F138-03 and F139-03 [22]. A sample from the locking screw was taken. Cutting, mounting, and polishing were performed to prepare the sample. The polishing was done with different grades of silicon carbide papers (320-600 grit) and diamond abrasive solutions $(9-0.01 \mu \mathrm{m})$. After the polishing, X-ray energy dispersive spectroscopy (EDS, Thermo Fisher Scientific, Hillsboro, OR, USA) was performed on the screw sample surface, and the results were compared with the ASTM standards F138-03 and F139-03 reported for stainless steel 316L to ensure that there is no significant difference that might have caused the failure $[18,23]$. Figure 3 shows the peaks of different element weight percent in the screw, and the data on each area is summarized in Table 3. Additionally, ASTM standard F139-03 has set additional requirements to ensure that the material meets the specifications, which is shown in Equation (1):

$$
\% \mathrm{Cr}+(3.3 \times \% \mathrm{Mo}) \geq 26.0
$$

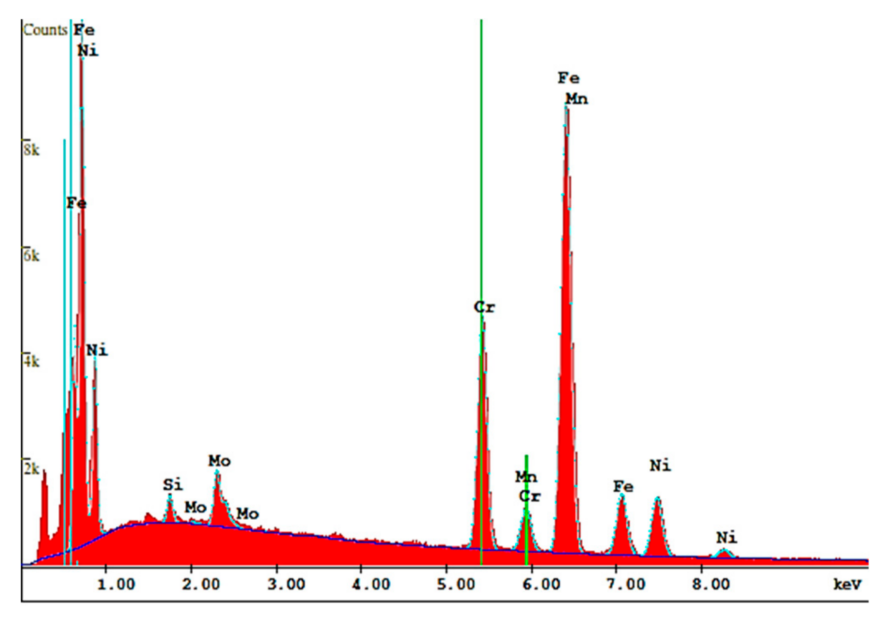

Figure 3. Energy dispersive $X$-ray analysis shows the peaks of different element weight percent in the cortical screw sample. 
Table 3. X-ray energy dispersive spectroscopy (EDS).

\begin{tabular}{cccccc}
\hline \multirow{2}{*}{ Composition } & $\begin{array}{c}\text { ASTM Standards } \\
\text { F138-03 and F139-03 }\end{array}$ & \multicolumn{3}{c}{ Screw } \\
\cline { 2 - 6 } & (Min-Max) & Area 1 & Area 2 & Area 3 & Average \\
\cline { 2 - 6 }$\% \mathrm{Mn}$ & $0-2.04$ & 1.63 & 1.51 & 1.62 & 1.57 \\
$\% \mathrm{Si}$ & $0-0.80$ & 0.62 & 0.63 & 0.42 & 0.56 \\
$\% \mathrm{Cr}$ & $16.80-19.20$ & 18.57 & 18.68 & 18.71 & 18.65 \\
$\% \mathrm{Mo}$ & $2.15-3.10$ & 2.97 & 3.09 & 2.36 & 2.81 \\
$\% \mathrm{Ni}$ & $12.85-15.15$ & 14.83 & 14.94 & 14.63 & 14.8 \\
\hline
\end{tabular}

The screw confirmed to the ASTM standard and there is no significant difference that might have caused the failure.

\section{Computational Simulations of Failures}

\subsection{Finite Element Analysis}

Three-dimensional models of the plate and the screws: cortical, locking, and cannulated were constructed using SolidWorks (Dassault Systèmes SolidWorks Corp., Concord, MA, USA) and imported in ANSYS Workbench 16.2 (ANSYS Inc., Canonsburg, PA, USA) to simulate the loading conditions and regions of stress development. The dimensions of the cortical, locking, and cannulated screws were taken from the Synthes brochure [24], and the PHILOS plate was measured from the submitted samples, Figure 4. Models were generated depending on patient-specific geometric information that was obtained manually from the X-ray images. The modeling of each screw has depended on the angle of its insertion inside the bone of this patient. However, locking screw placement angles were not clearly visible in the X-ray due to the presence of too many screws that were used in the fixation, Figure 5. That being said, the locking screws placement angles were measured manually by inserting locking screws inside a sample plate. Figure 6 shows the angles of the locking screws at level A. Locking screws at level A were inserted slightly upward with a $30^{\circ}$ angle above the neutral axis of the center of the screw hole and parallel to each other. The locking screws at level B were inserted perpendicular to the plate with an inward $30^{\circ}$ angle. The locking screws at level $\mathrm{C}$ were inserted upward with a $40^{\circ}$ angle above neutral axis and outward $30^{\circ}$ angle. The locking screws at level D were inserted slightly upward with a $10^{\circ}$ angle above the neutral axis. Finally, the locking screw at level E was inserted upward with a $30^{\circ}$ angle above the neutral axis and slightly outward. The heads of the locking screws were fixed with no displacement allowed. Additionally, the material properties of stainless steel 316L were assigned according to the ASTM standard [22], shown in Table 4. The cortical and cancellous components were modeled with a $12.7 \mathrm{GPa}$ and a $0.9 \mathrm{GPa}$ modulus of elasticity and a 0.3 and a 0.2 Poisson's ratio, respectively [25]. Materials were treated as homogeneous, isotropic, and a linear elastic analysis was carried out. All the results were within the limitation of this assumption assuming all loads transferred from bone to the plate. Figure 7 shows the loading conditions that have been applied to the plate and the screws.

It is claimed that when a PHILOS plate is closed with all the screw holes, the fixation is stable and fracture union takes place with time. However, with the current subject, the device started to fail before the bone union took place, which caused some displacement and led the screws to fail after two years, visible when X-rays were taken. We ignored the effect of screw failure on the adjacent level screws both in terms of construct plate-screw placement angles and load transfer. As there is no viable way to identify the amount of screw micro-motion in this construct, it was assumed that displacement in the cortical screws within the range of $0.05-0.25 \mathrm{~mm}$ occurring within the few months after load bearing based on our research on hybrid constructs where the stiffness drop occurs within the first 5000 fatigue cycles [7] resulting in altering the coefficients of friction between the screws and bone; 0.5 with all screws intact to 0.1 when screws began to fail. All the locking screws were assumed to be fixed, 
while some displacement was allowed for the cortical screws along the $x$-axis, as shown in Figure 8, simulating human gait to reflect loading and deformation. The loading was applied in two steps; (1) the preload torque for the installation of the screw, and (2) the axial loads. The applied load on the ankle joint might reach 3.5 times of the body weight in the gait cycle during the push-off stage [26]. The body weight of the patient was assumed to be $80 \mathrm{~kg}$ in this study. However, for patients with abnormal gait cycles, the applied load may reach four times of the body weight $(3000 \mathrm{~N})$ or higher. To simulate the contact analysis in the model, the target and contact surfaces between the plate and bone, the plate and screws, and bone and screws were defined by not merging the nodes between the components and assuring the union and the transformation of the loads and the deformation between the plate, screws, and bone with a coefficient of friction of 0.4 between the plate and the bone [27], 0.35 between the plate and the screws [28], and five different coefficients of friction were obtained between the screws and the bone $(0.1,0.2,0.3,0.4$, and 0.5) [27]. Furthermore, five different axial loads were tested to observe the PHILOS device in normal and extreme situations with axial loads ranging from $500-2000 \mathrm{~N}$ with a torque load $5.0 \mathrm{Nm}[29,30]$. The loading in the screws had been inclined to match with the insertion angle of each of the screws. In addition, two screw pattern designs (Figure 8) were assumed in order to investigate the effect of screw position on the maximum stress of the plate: design (A) where the screws inserted at levels $A, C, D$, and $E$, and design (B) where the screws inserted at levels A, B, C, and E, as shown in Figure 8, and the loading and boundary conditions are shown in Figure 7. In addition, the tetrahedral element type was used in this study. The FE meshing was automatically adapted through Ansys, where convergence tools were used with 5\% convergence, which resulted in approximately 50,000 elements and 85,000 nodes, as shown in Figure 7. Some studies suggested removing of unused screw holes from the model, however, in this study all the holes were included in the design, and only filled with screws per designs A and B, Figure 8.

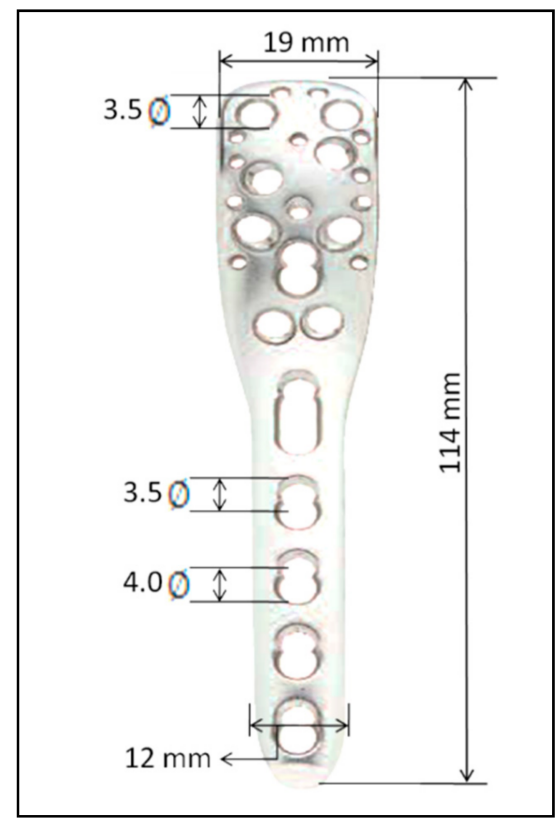

Figure 4. The dimensions of the $3.5 \mathrm{~mm}$ standard locking compression plates (LCP) proximal humerus locking plate. 


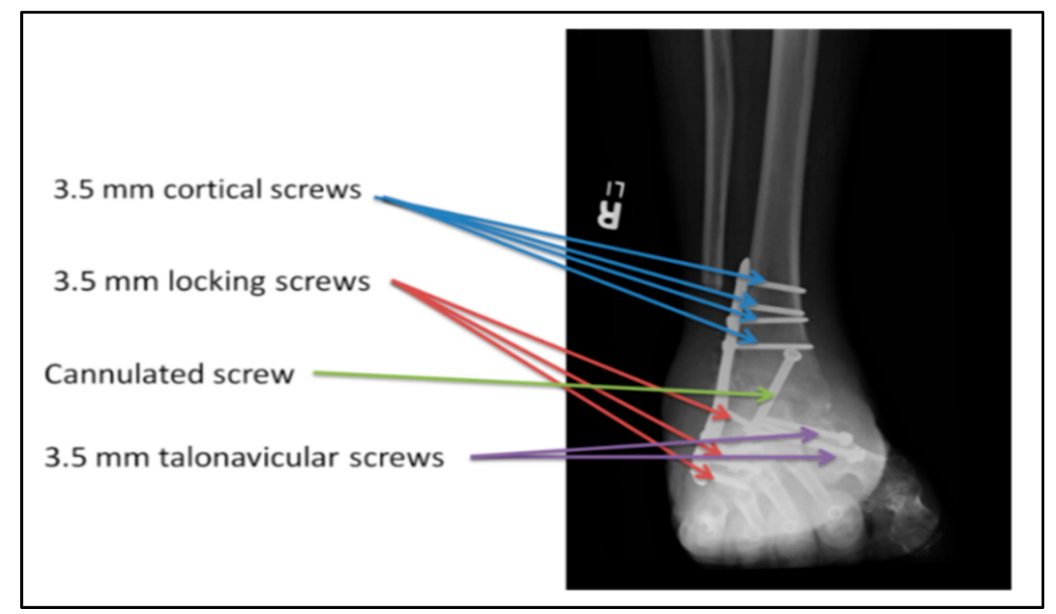

Figure 5. X-ray image showing the screws used in the tibiotalocalcaneal fixation.

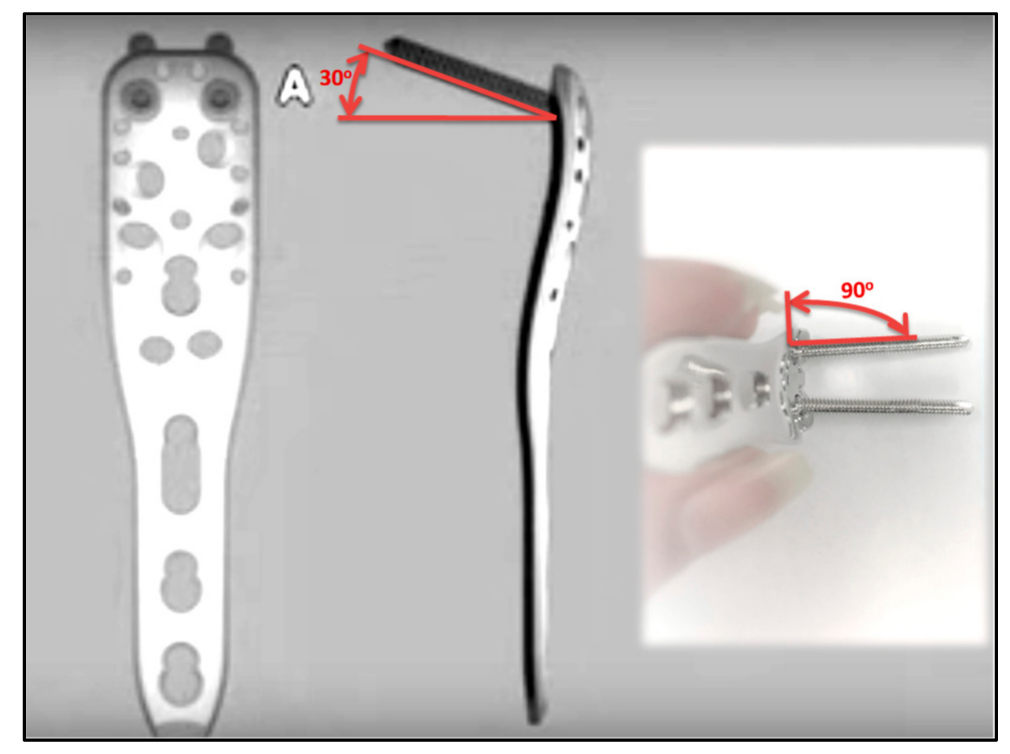

Figure 6. Variable angle placement of the locking screws at level A.

Table 4. Stainless Steel 316L material properties [22].

\begin{tabular}{cc}
\hline Material Properties & 316L Stainless Steel \\
\hline Elastic Modulus $(\mathrm{GPa})$ & 200 \\
Shear Modulus $(\mathrm{GPa})$ & 82 \\
Poisson's Ratio & 0.265 \\
Mass Density $\left(\mathrm{g} / \mathrm{m}^{3}\right)$ & 8.027 \\
Tensile Strength $\left(\mathrm{N} / \mathrm{mm}^{2}\right)$ & 860 \\
Yield Strength $\left(\mathrm{N} / \mathrm{mm}^{2}\right)$ & 690 \\
\hline
\end{tabular}




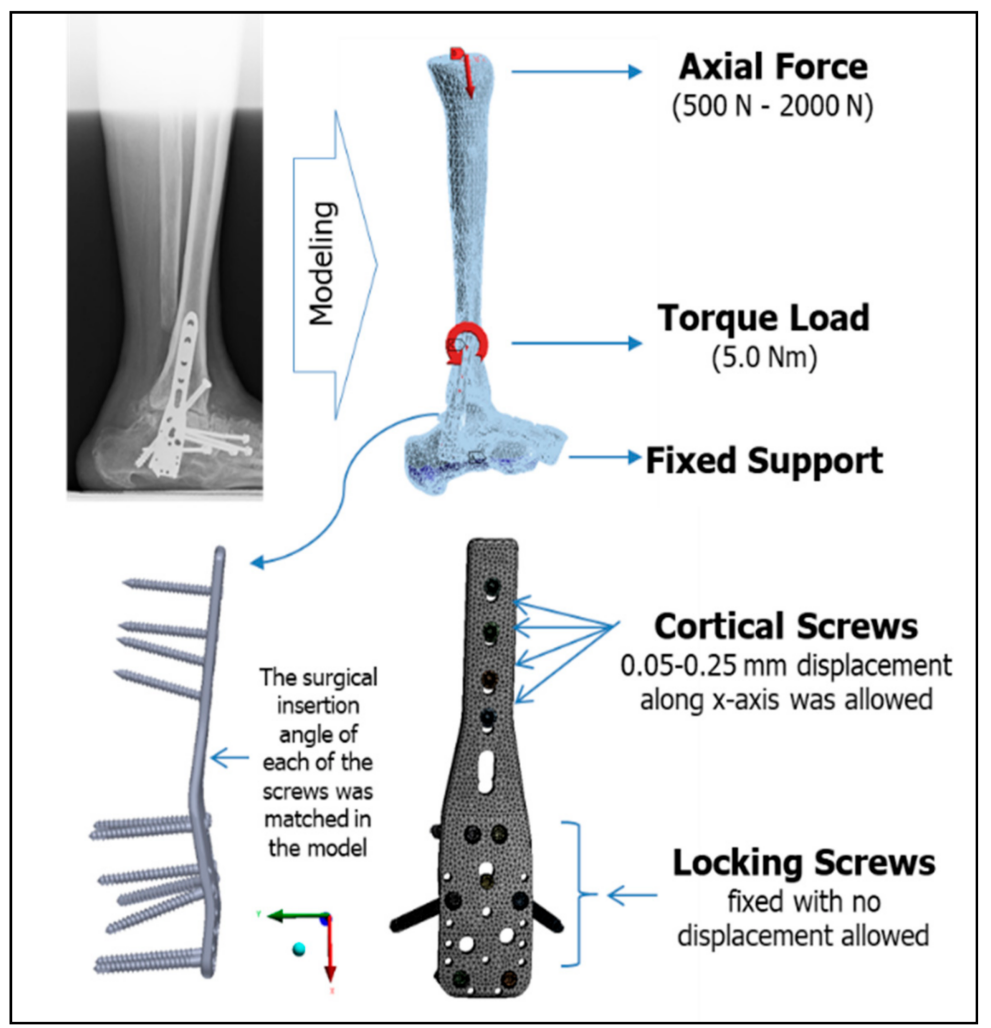

Figure 7. The loading and boundary conditions applied on the model.
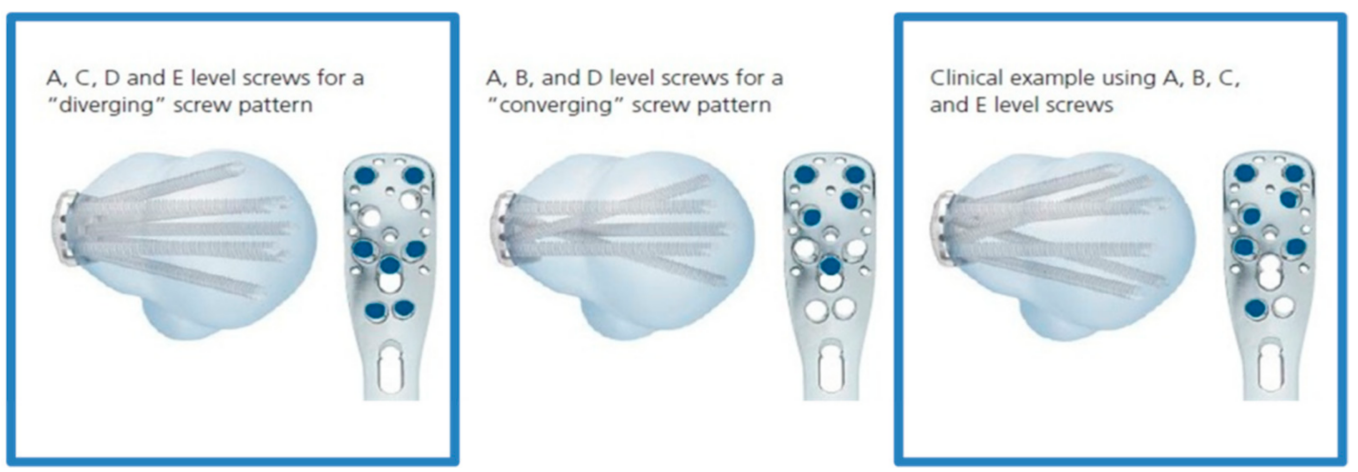

Figure 8. Screw pattern designs. Design A (left) and design B (right) [17].

\subsection{The Results}

The maximum von Mises stress in the plate was obtained with two screw pattern designs, five axial loads and coefficients of friction between the screw and the plate, and five cortical screw displacements, and the results are summarized in Table 5. Figure 9 shows the von Mises stresses of the 316L SS plate with screw design $\mathrm{B}, 500 \mathrm{~N}$ axial load, 0.5 coefficient of friction between the screw and the plate, and $0.1 \mathrm{~mm}$ cortical screw displacement. It was observed that the maximum stresses are in the levels B-E, which validates the visual and fractography examinations. Additionally, the maximum stresses were between 201 and $346 \mathrm{MPa}$ for 500-750 N axial loading, which is significantly lower than the yield strength $\left(\sigma_{\mathrm{y}}=690 \mathrm{MPa}\right)$ of the material. However, for the fatigue limit at $10^{7}$ cycles, the maximum stresses should be equal to, or less than, $440 \mathrm{MPa}$ to be in the safe region [31]. On the other hand, the maximum stresses were between 504 and $692 \mathrm{MPa}$ for 1500-2000 N axial loading, which is significantly higher than the failure criteria used. At this level, the developed stresses are likely to cause plastic deformation and failure prematurely. If the environmental effects were included, the corrosion fatigue 
crack propagation may activate at this level of loading. Since the ankle deformity gives rise to the increased level of force development in the range of 4-8 times the body weight, the extrapolated von Mises stress may reach as high as $900 \mathrm{MPa}$. In addition, the simulations show that higher coefficients of friction reduce the von Mises stress for both pattern designs and for different loading conditions. As a result estimation of the actual loading behavior of the plate from the activities of daily living of the individual, together with mechanical parameters such as the coefficient of friction, loosening, and axial loading in the screw and plate, will be very difficult to isolate and predict the combined mechanisms and failure behavior.

Table 5. The maximum von Mises stresses of the plates were obtained for five different loads, five coefficients of friction, five cortical screws displacement, and two screw pattern designs.

\begin{tabular}{|c|c|c|c|c|c|c|c|c|c|c|c|}
\hline \multirow{3}{*}{$\begin{array}{c}\text { Axial } \\
\text { Force }(\mathrm{N})\end{array}$} & \multirow{3}{*}{$\begin{array}{l}\text { Coefficient } \\
\text { of Friction }\end{array}$} & \multicolumn{5}{|c|}{ Design A } & \multicolumn{5}{|c|}{ Design B } \\
\hline & & \multicolumn{10}{|c|}{ Non-Locking Screws Displacement (mm) } \\
\hline & & 0.05 & 0.10 & 0.15 & 0.20 & 0.25 & 0.05 & 0.10 & 0.15 & 0.20 & 0.25 \\
\hline \multirow{5}{*}{500} & 0.10 & 219.81 & 221.90 & 224.19 & 226.72 & 229.49 & 220.86 & 222.95 & 225.24 & 227.76 & 230.54 \\
\hline & 0.20 & 210.54 & 211.70 & 212.97 & 214.38 & 215.92 & 211.59 & 212.75 & 214.02 & 215.42 & 216.97 \\
\hline & 0.30 & 205.39 & 206.03 & 206.74 & 207.52 & 208.38 & 206.44 & 207.08 & 207.79 & 208.57 & 209.43 \\
\hline & 0.40 & 202.53 & 202.88 & 203.28 & 203.71 & 204.19 & 203.58 & 203.93 & 204.33 & 204.76 & 205.24 \\
\hline & 0.50 & 200.93 & 201.13 & 201.35 & 201.59 & 201.86 & 201.99 & 202.19 & 202.40 & 202.64 & 202.91 \\
\hline \multirow{5}{*}{750} & 0.10 & 330.26 & 333.39 & 336.83 & 340.62 & 344.78 & 331.29 & 334.42 & 337.86 & 341.65 & 345.81 \\
\hline & 0.20 & 316.35 & 318.09 & 320.00 & 322.10 & 324.42 & 317.38 & 319.12 & 321.03 & 323.14 & 325.45 \\
\hline & 0.30 & 308.62 & 309.59 & 310.65 & 311.82 & 313.11 & 309.66 & 310.62 & 311.69 & 312.85 & 314.14 \\
\hline & 0.40 & 304.33 & 304.87 & 305.46 & 306.11 & 306.82 & 305.37 & 305.90 & 306.49 & 307.14 & 307.85 \\
\hline & 0.50 & 301.95 & 302.24 & 302.57 & 302.93 & 303.33 & 302.98 & 303.28 & 303.61 & 303.97 & 304.36 \\
\hline \multirow{5}{*}{1000} & 0.10 & 440.70 & 444.87 & 449.46 & 454.50 & 460.06 & 441.72 & 445.89 & 450.48 & 455.53 & 461.08 \\
\hline & 0.20 & 422.15 & 424.47 & 427.02 & 429.82 & 432.91 & 423.18 & 425.49 & 428.04 & 430.85 & 433.93 \\
\hline & 0.30 & 411.85 & 413.14 & 414.56 & 416.11 & 417.83 & 412.88 & 414.16 & 415.58 & 417.14 & 418.85 \\
\hline & 0.40 & 406.13 & 406.84 & 407.63 & 408.50 & 409.45 & 407.15 & 407.87 & 408.66 & 409.52 & 410.47 \\
\hline & 0.50 & 402.95 & 403.35 & 403.78 & 404.26 & 404.79 & 403.97 & 404.37 & 404.81 & 405.29 & 405.82 \\
\hline \multirow{5}{*}{1500} & 0.10 & 551.13 & 556.34 & 562.08 & 568.39 & 575.33 & 552.15 & 557.36 & 563.10 & 569.41 & 576.35 \\
\hline & 0.20 & 527.95 & 530.85 & 534.04 & 537.54 & 541.40 & 528.97 & 531.87 & 535.06 & 538.56 & 542.42 \\
\hline & 0.30 & 515.08 & 516.68 & 518.46 & 520.40 & 522.55 & 516.10 & 517.70 & 519.48 & 521.42 & 523.56 \\
\hline & 0.40 & 507.92 & 508.82 & 509.80 & 510.88 & 512.07 & 508.94 & 509.84 & 510.82 & 511.90 & 513.09 \\
\hline & 0.50 & 503.95 & 504.44 & 504.99 & 505.59 & 506.25 & 504.97 & 505.46 & 506.01 & 506.61 & 507.27 \\
\hline \multirow{5}{*}{2000} & 0.10 & 661.56 & 667.82 & 674.70 & 682.28 & 690.61 & 662.58 & 668.84 & 675.72 & 683.29 & 691.62 \\
\hline & 0.20 & 633.75 & 637.23 & 641.05 & 645.26 & 649.88 & 634.77 & 638.24 & 642.07 & 646.27 & 650.90 \\
\hline & 0.30 & 618.30 & 620.23 & 622.35 & 624.69 & 627.26 & 619.31 & 621.25 & 623.37 & 625.71 & 628.28 \\
\hline & 0.40 & 609.71 & 610.79 & 611.97 & 613.27 & 614.69 & 610.73 & 611.80 & 612.98 & 614.28 & 615.71 \\
\hline & 0.50 & 604.94 & 605.54 & 606.20 & 606.92 & 607.71 & 605.96 & 606.56 & 607.21 & 607.93 & 608.73 \\
\hline
\end{tabular}

On the other hand, the maximum von Mises stresses increased with the increase in cortical screw displacements, as the screws began to fail, as shown in Figures 10 and 11. The maximum von Mises stresses of the cortical screws occurred near the head of the screw when the screw was perpendicular to the plate, as shown in Figure 12 (will be further discussed in Section 7). However, the maximum von Mises stress of the cortical screw was near the middle of the screw when the screw was at an upward angle, which will be further discussed in Section 7. In addition, the maximum von Mises stresses of the locking screws were distributed across the screws and were higher at levels A, C, and E, where the screws have slightly upward angles. Figure 13 shows the von Mises stress of the locking screw at level $\mathrm{C}$ and the screw insertion angles. Table 6 shows the maximum von Mises stresses of the cortical and locking screws. Finally, the von Mises stress of the cannulated screw is shown in Figure 14, and it is observed that the stresses are higher in the shaft of the cannulated screw. 


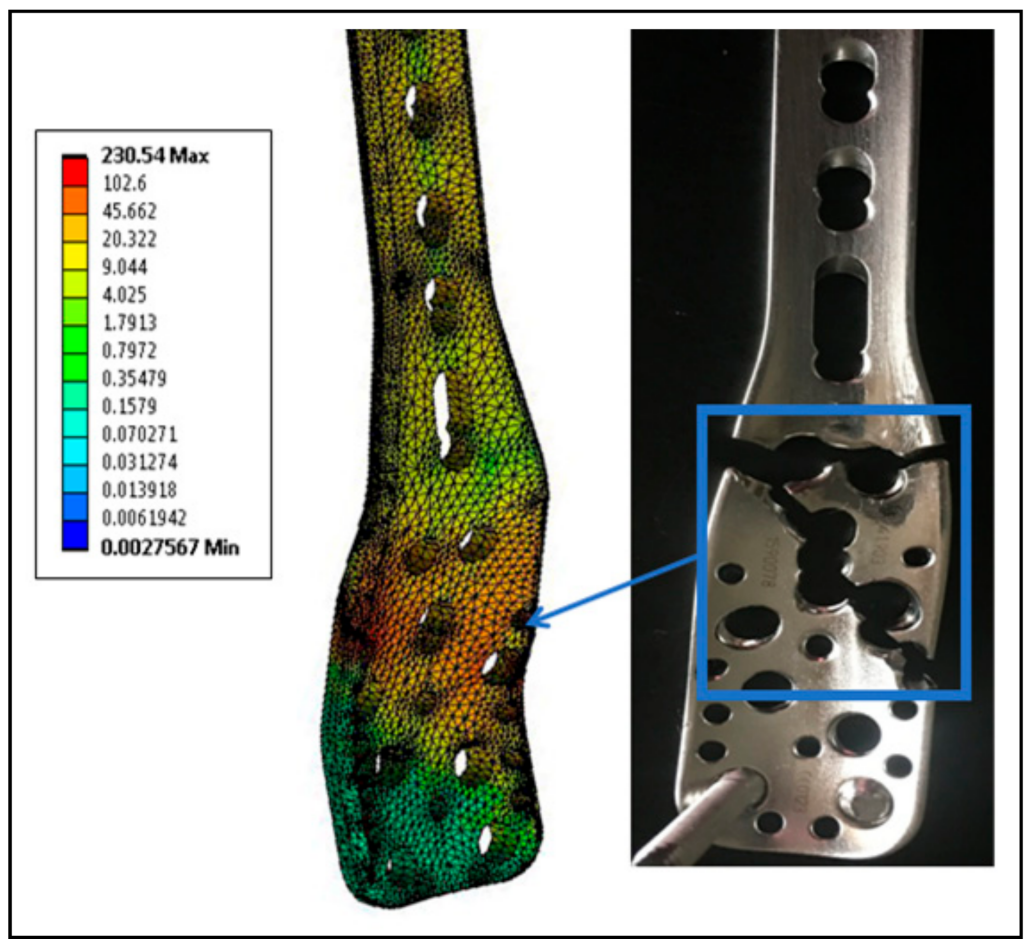

Figure 9. The von Mises stresses in the 316L SS plate with screw design B, $500 \mathrm{~N}$ axial load, 0.5 coefficient of friction between the screw and the plate, and $0.1 \mathrm{~mm}$ cortical screw displacement.

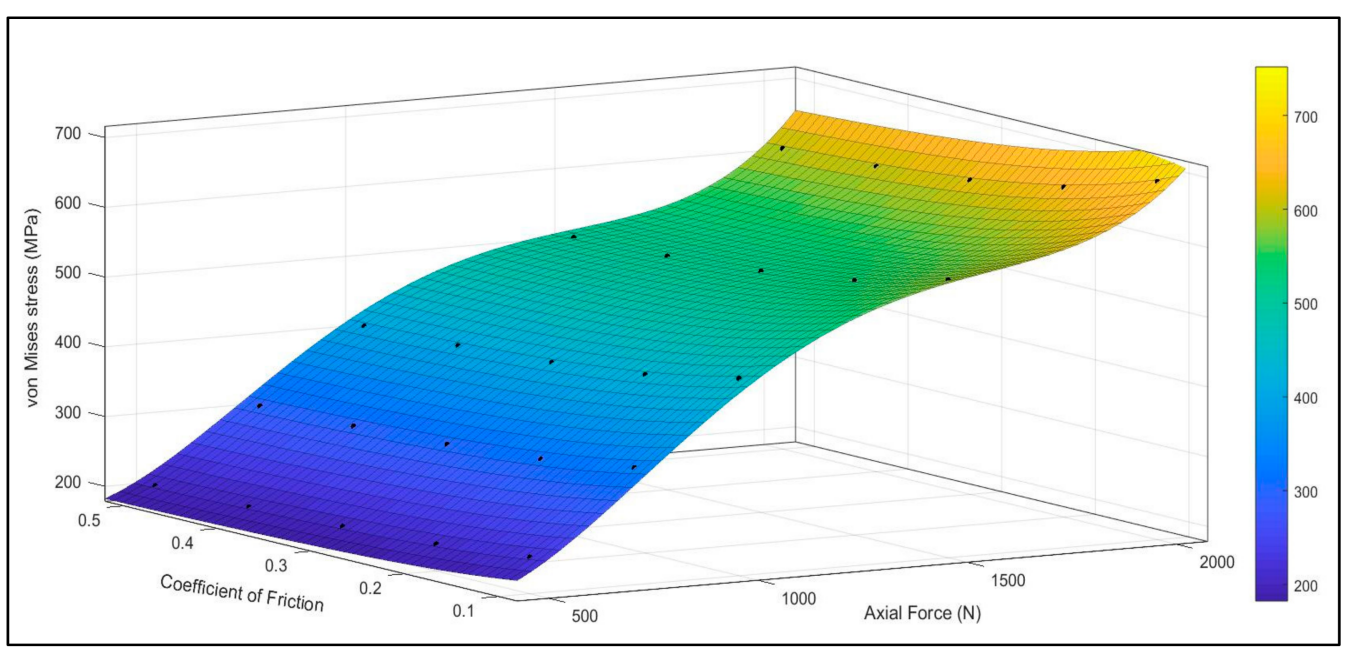

Figure 10. The surface plot of the maximum von Mises stresses in the 316L SS plate with screw design $\mathrm{B}$ and $0.25 \mathrm{~mm}$ cortical screw displacement vs. the coefficient of friction (COF) and the axial force. 


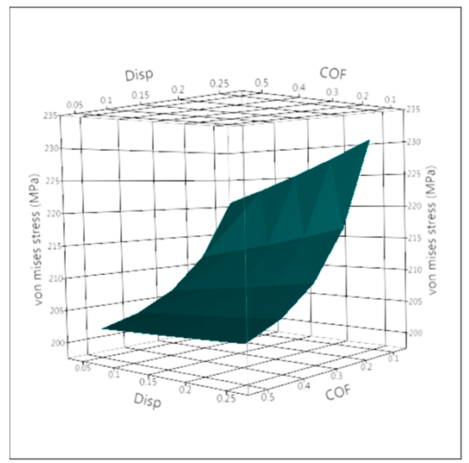

(a) $500 \mathrm{~N}$

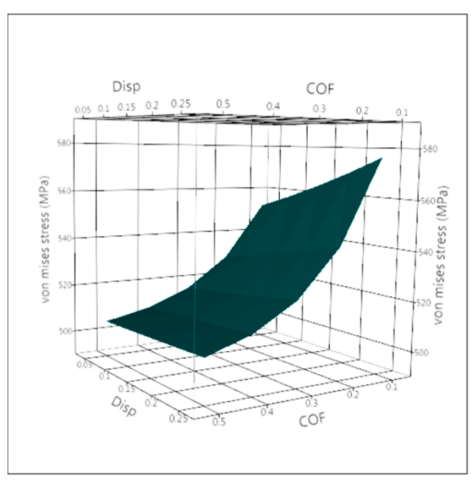

(d) $1500 \mathrm{~N}$

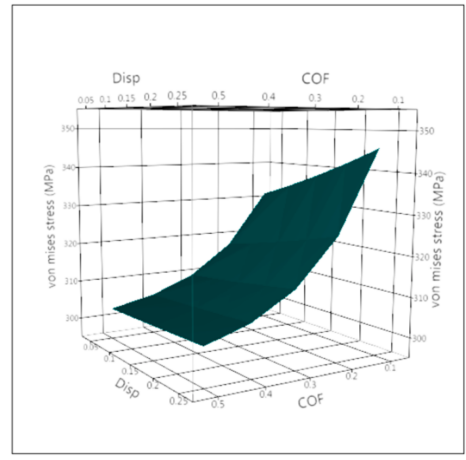

(b) $750 \mathrm{~N}$

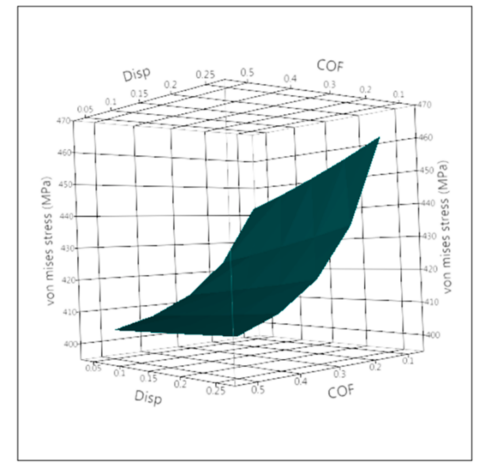

(c) $1000 \mathrm{~N}$

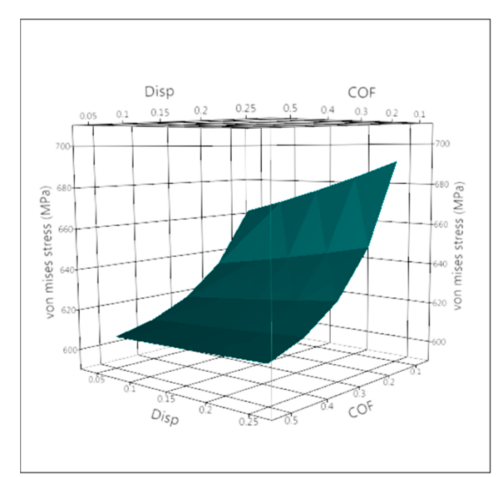

(e) $2000 \mathrm{~N}$

Figure 11. The surface plot of maximum von Mises stresses in the 316L SS plate vs. the coefficient of friction (COF) and the cortical screw displacement (mm) for different axial loads (a) $500 \mathrm{~N},(\mathbf{b}) 750 \mathrm{~N}$, (c) $1000 \mathrm{~N},(\mathbf{d}) 1500 \mathrm{~N},(\mathbf{e}) 2000 \mathrm{~N}$.

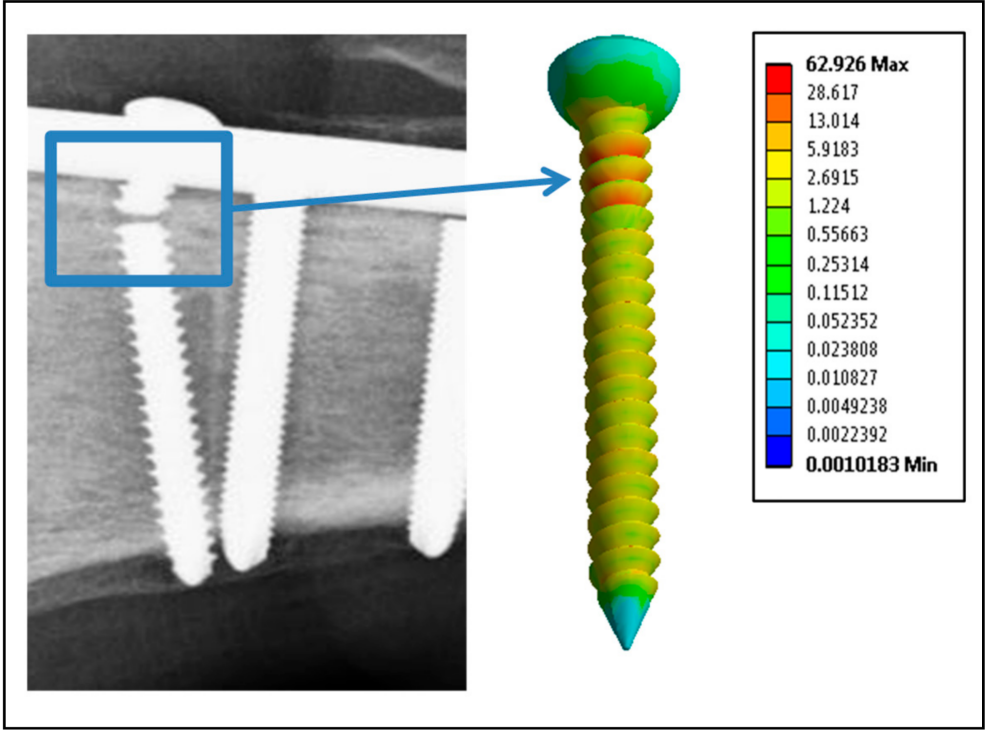

Figure 12. Comparing a two-year post operation X-ray image with the von-Mises stress of the 316L SS cortical screw (CS3). 

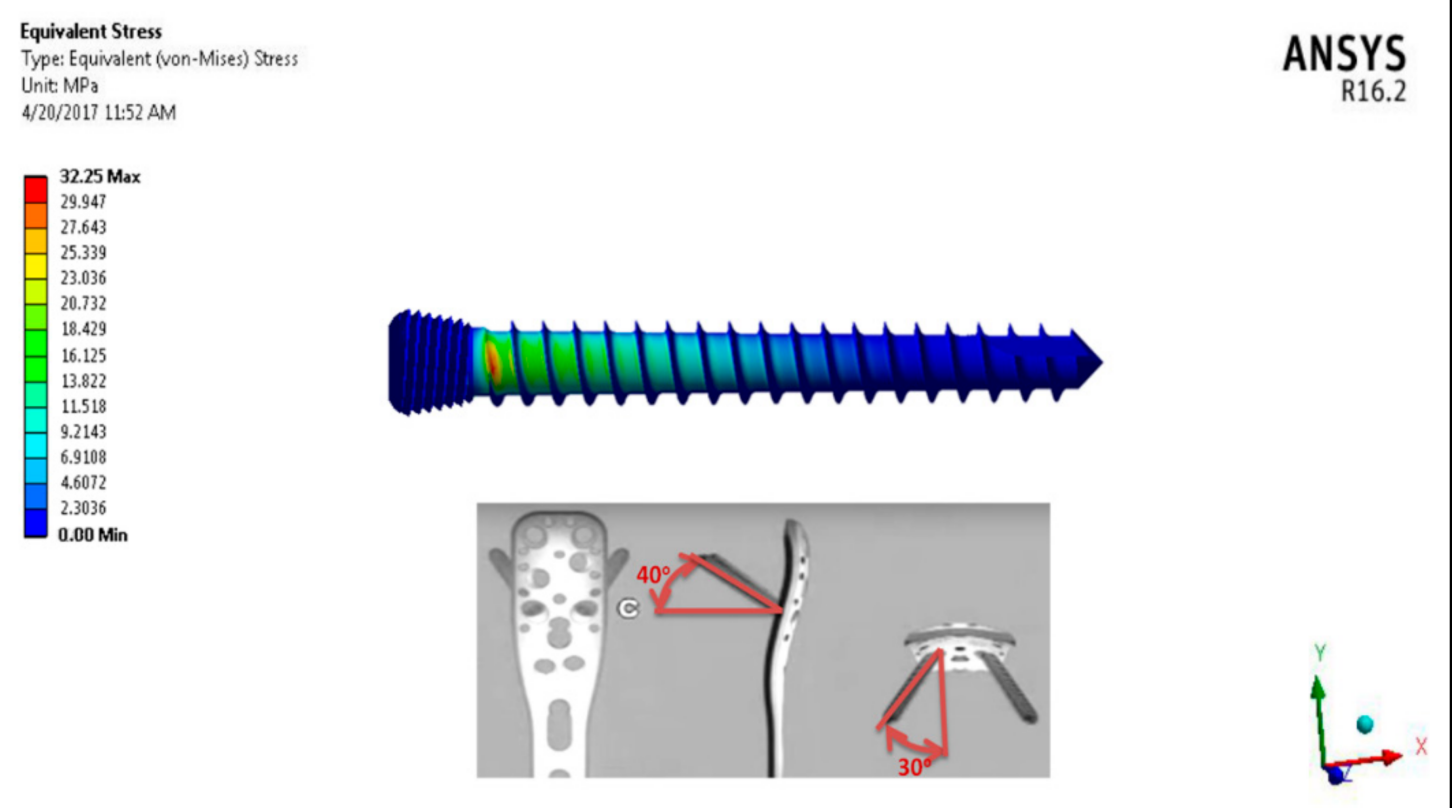

Figure 13. The von Mises stress of the 316L SS locking screw at level C and the screw insertion angles.

Table 6. The maximum von Mises stresses in the screws.

\begin{tabular}{cccccccccc}
\hline Description & \multicolumn{3}{c}{ Cortical Screws } & \multicolumn{4}{c}{ Locking Screws } \\
\hline The Screw & CS1 & CS2 & CS3 & CS4 & A & B & C & D & E \\
Maximum Stress (MPa) & 54.164 & 56.6316 & 62.926 & 59.627 & 31.138 & 26.4 & 32.25 & 28.04 & 31.9 \\
\hline
\end{tabular}

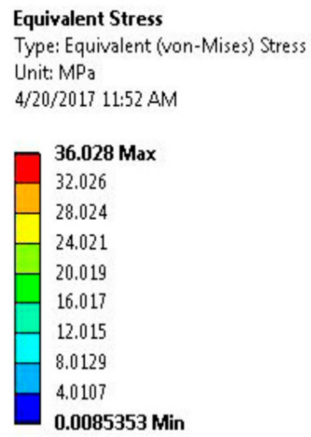

24.021

20.019

16.017

12.015

8.0129

4.0107

$0.0085353 \mathrm{Min}$

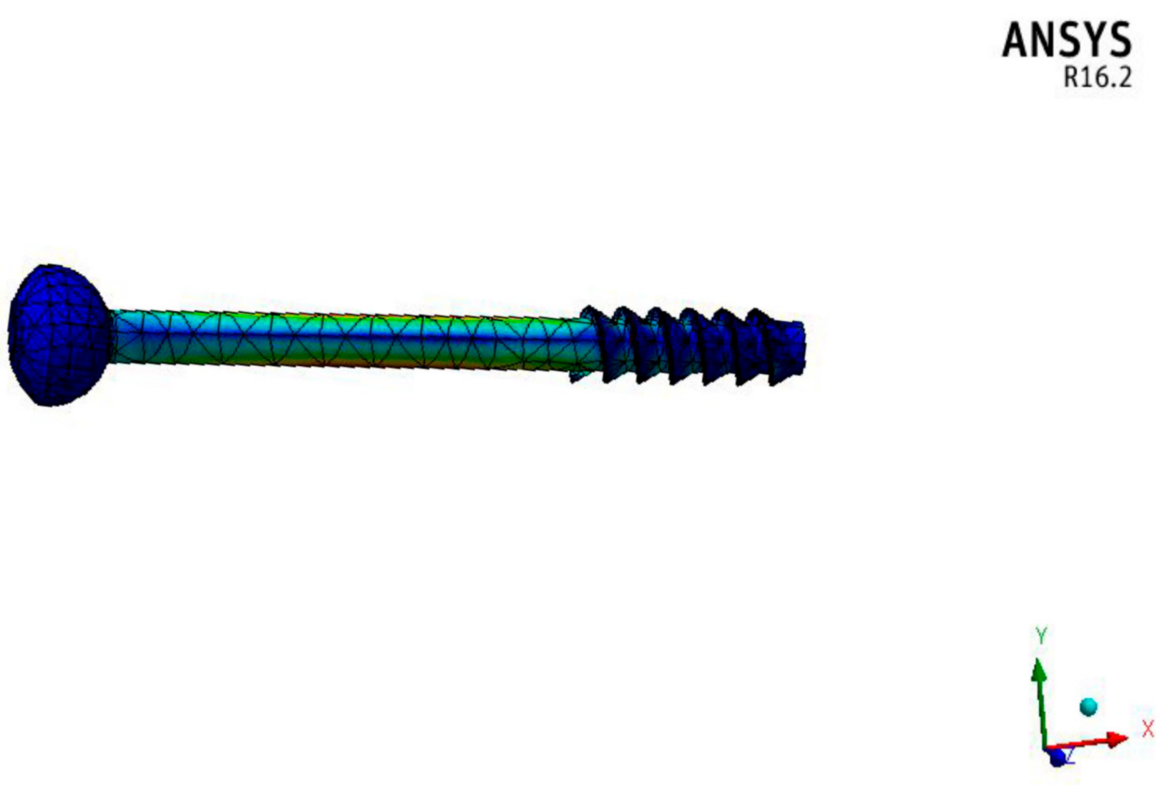

Figure 14. The von-Mises stresses in the cannulated screw. 


\section{Discussion}

This paper not only examines the PHILOS plate computational simulations, but also examines the failure mechanisms of all the screws that failed. On visual examination, it can be noticed that the crack initiated from under one of the locking holes near the middle of the plate. Observing the plate under optical microscopy indicated that the surface of the plate had a considerable amount of scratches and pitting. Seventy-five percent of the cortical screws and $42.8 \%$ of the locking screws fractured into two pieces. Chemical, qualitative analysis of our results shows that the screw confirmed to the ASTM standards F138-03 and F139-03 and there is no significant difference that may have caused the failure.

Optical and scanning electron microscopes were used to document the fracture surface characteristics, such as extensive scratching, plastic deformation, rubbed surfaces, discoloration, and pitting, along with cleavage, cracking, deposits of debris, striations, and dimples. Fractographs show a quasi-cleavage fracture. Azevedo [19], Kanchanomai et al. [20], and Majid et al. [32] showed similar observations that the corrosion-fatigue mechanism was responsible for the failure of plates. However, Sivakumar et al. [33] showed that the failure of plates could be a result of improper fixation. On the fracture surface of the cortical screws, we noticed the presence of striations, microcracks, and rubbed surfaces. The presence of the inclusions, as presented in paper I [16] for this material, increased the pitting susceptibility of SS316L and possible transitioning to corrosion fatigue cracking. FEM analysis clearly shows that at any level of load bear, the developed stresses will cause plastic deformation at the sites of screw holes and this plasticity will initiate a crack. Thapa et al. showed a similar fractographic examination for the locking plate [34]. Indications of these features show that the plate failed by corrosion fatigue. However, overloading separated the screws into two parts. Radiographic evidence shows that the screws failed ahead of the plate from the proximal end. Finally, fractographic examination of the cortical and locking screws supports the mechanism of corrosion-fatigue fracture from crack initiation sites due to the presence of inclusion bodies and pits.

In addition, two screw pattern designs were assumed in order to investigate the effect of the screw position on the maximum stress of the plate. Some studies suggested the removal of unused screw holes from the model, however, in this study all the holes used in the simulation provided higher fixation strength and stability. The results of the computational simulation showed that the maximum stresses simulated the loading conditions and regions of stress development. The simulation showed that having higher coefficients of friction reduces the von Mises stresses for both pattern designs and for different loading conditions. On the other hand, the maximum von Mises stresses of the PHILOS plate increased with the increase in cortical screw displacements. The results for the visual, fractography, and quantitative examinations of the cortical, locking, and cannulated screws are summarized in Table 7. 
Table 7. Visual, fractography, and quantitative examinations of the cortical, locking, and cannulated screws.

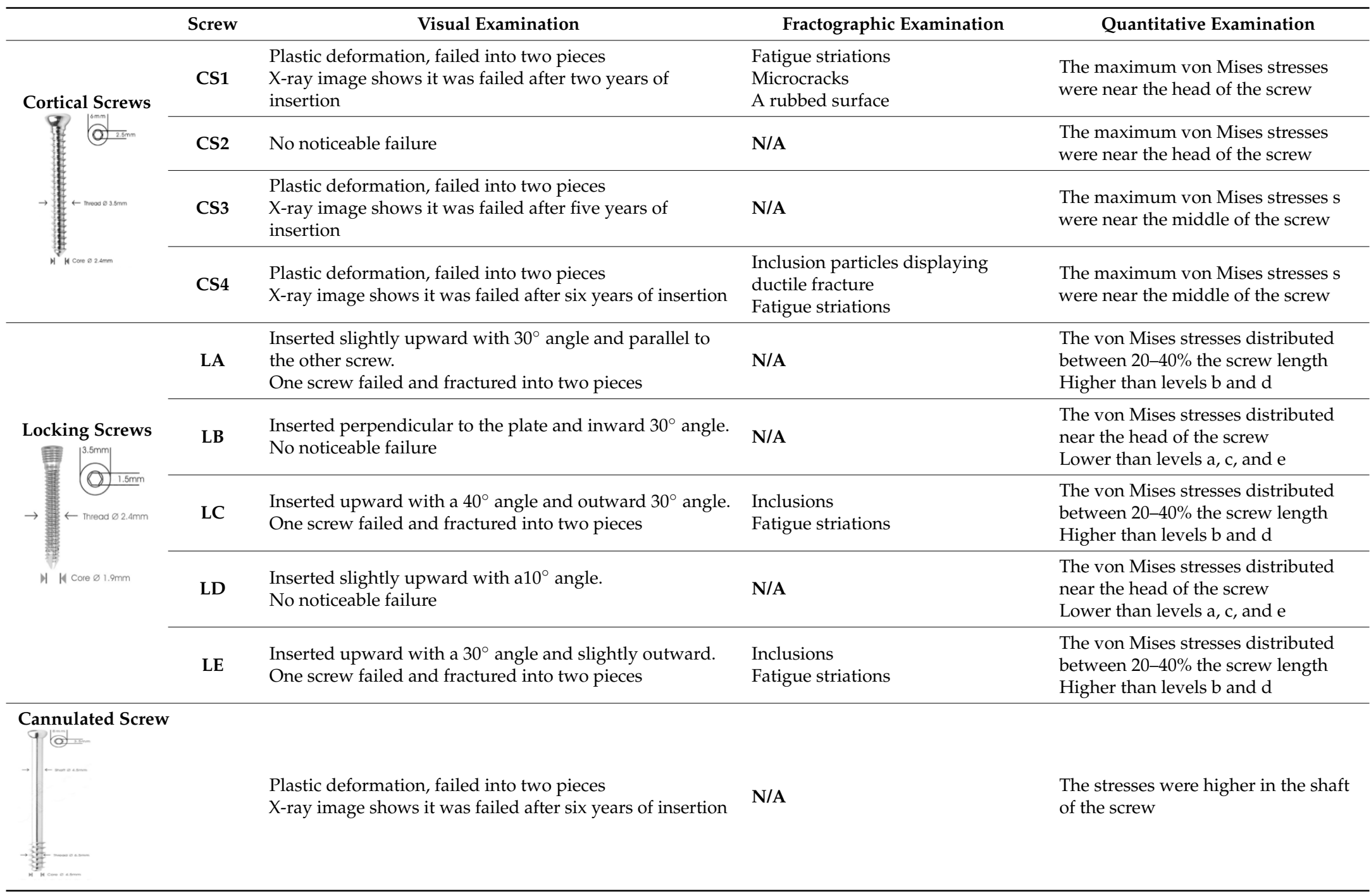


The maximum von Mises stresses of the cortical screws were near the head of the screw when the screw was perpendicular to the plate and near the middle when the screws were at upward angles. If we compare the von Mises stresses of the four cortical screws across the cortical screws length, it was observed that the maximum stresses are almost similar for all the screws, but the position of the maximum stresses varied depending on the angle of the screws, as shown in Figure 15. Additionally, the graph shows that the stresses are, at a minimum, at the head of the $\mathrm{C} 1$ and $\mathrm{C} 2$ screws. Then, a sharp increase in the stresses can be noticed at the shaft of the screw near the head, as this is the area where the screw cuts through the cortical bone and is exposed to the axial load of the bone. Then the stress distribution decreased gradually. On the other hand, C3 and C4 cortical screws were at an upward angle. This angulation increased the stress by $165 \%$ on the shaft of the screw than the head of the screw. In the case of locking screws, the maximum von Mises stresses were distributed across the screws. However, the maximum von Mises stresses were only $110 \%$ higher at levels A, C, and E where the screws have slightly upward angles. Figure 16 shows a comparison between the von Mises stresses across the locking screw length. It can be noticed from the graph that the maximum stresses were near the heads of the screws and as the screws entering the cortical bone. Finally, it was observed that the stresses were $170 \%$ higher in the shaft of the cannulated screw than the head and the tip of the screw. In general, the maximum von Mises stresses experienced by the screws were lower than the fatigue stress limit. However, corrosion in this case may drastically affect the lifetime of the screws by reducing the number of cycles to failure. The numerical analysis was conducted to understand the impact of different factors on the maximum von Mises stresses of the locking compression plate. The statistical analysis showed that the applied load has a significant effect on the maximum stresses, but the screw pattern design does not have a significant effect. In summary, the fractographic examination of the cortical and locking screws supports the mechanism of corrosion-fatigue fracture from crack initiation sites due to the presence of pits and/or high plasticity regions. Additionally, the cracking followed by the rotating bending mechanisms since the axial load and torsion control that behavior. This study validates the physical failure with the computational simulations.

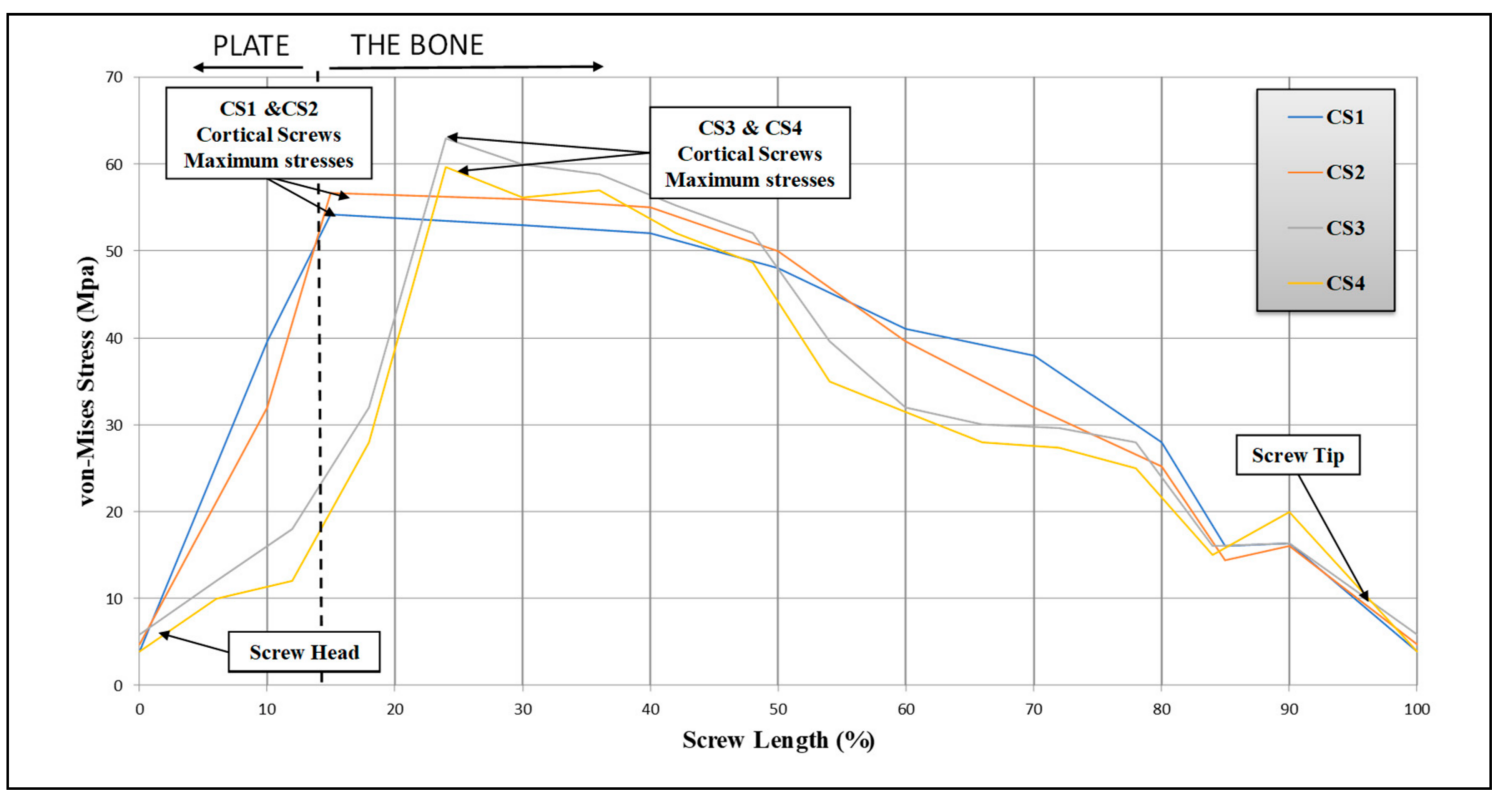

Figure 15. The von-Mises stresses of the 316L SS cortical screws across the screw length. 


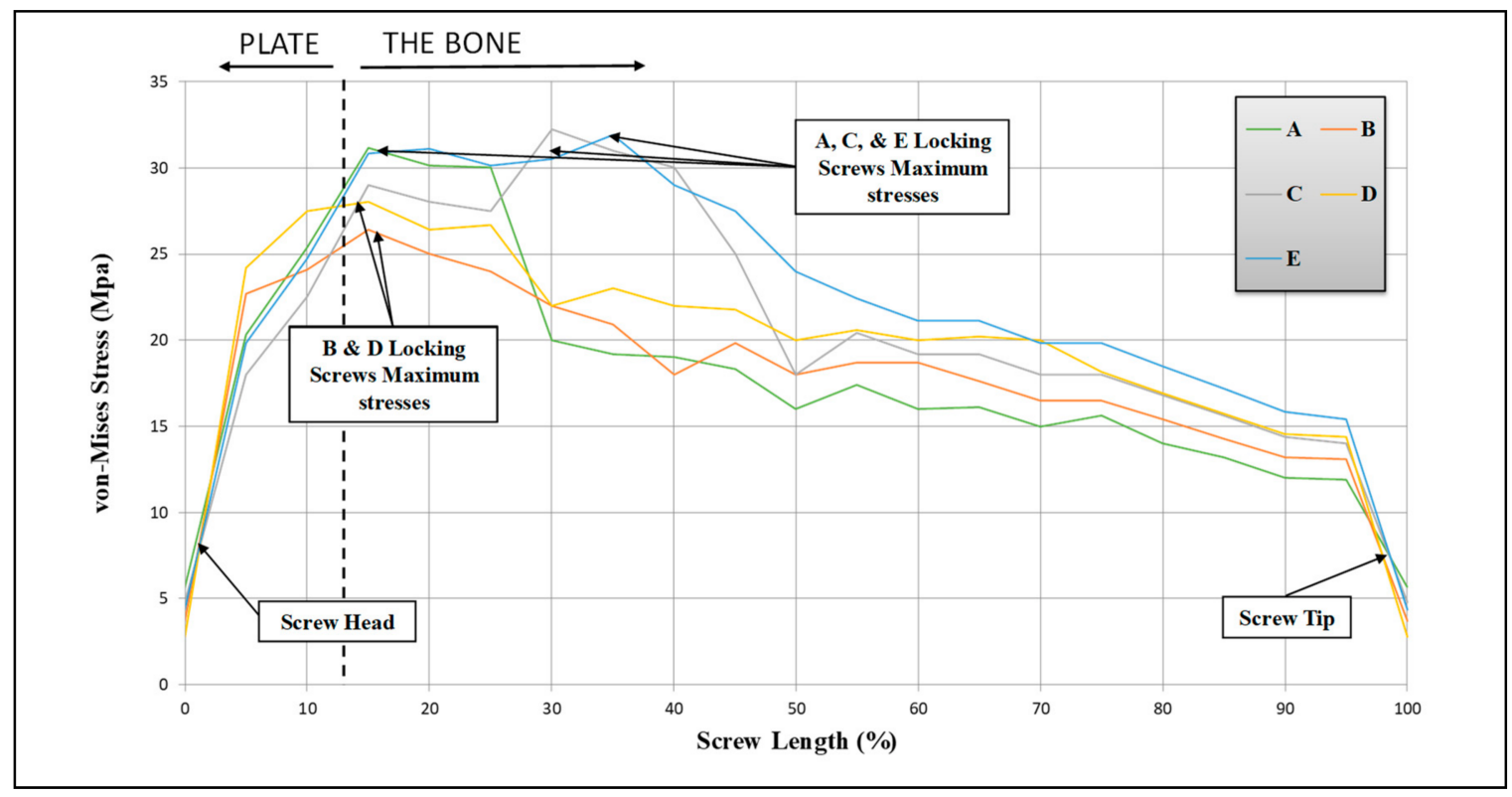

Figure 16. The von-Mises stresses of the 316L SS locking screws across the screw length.

\section{Conclusions}

Attempts were made to perform qualitative and quantitative failure analyses of the PHILOS construct in this paper. This study clarifies that there are several factors that, together, caused the mechanical and clinical failures of the system summarized below.

1. Fractographic examination of the cortical and locking screws supports the mechanism of corrosion-fatigue fracture from crack initiation sites due to the presence of inclusion bodies and pits and regions of high plastic strains due to load bear. The regular features, such as beach marks and striations, were present indicating fatigue and/or corrosion fatigue controlled the failure process.

2. The simulations showed that the maximum von Mises stresses of the PHILOS plate increased by $2.2 \%$ with the increase in cortical screw displacement as expected as the screws began to fail, giving rise to higher macro-motion of the construct at the same time lowering the coefficient of friction between the contacts.

3. The analysis of cortical screws showed that the stresses increased by $7.4 \%$ as the angle between the screw and the plate increased.

4. The stresses in the locking screws were lower than the cortical screws by $25.5 \%$, and this may be a result of the locking screws' fixed angles with less range of motion.

The finite element simulation of the plate validated the loading conditions and regions of stress development that supported the visual and fractographic examinations causing the physical failure of the PHILOS system.

Acknowledgments: Allen Jackson, Wright State University, Dayton, Ohio provided access to the SEM facility.

Author Contributions: Farah Hamandi performed the SEM analysis and texture related research, mechanical tests, and the theoretical aspects of the paper. Richard Laughlin performed the revision surgery and removed the device components. Tarun Goswami, led this research study, recruited students, verified the analytical methods and edited or written the body of the paper.

Conflicts of Interest: The authors declare no conflict of interest. 


\section{Appendix A}

\section{Fractographic Examination}

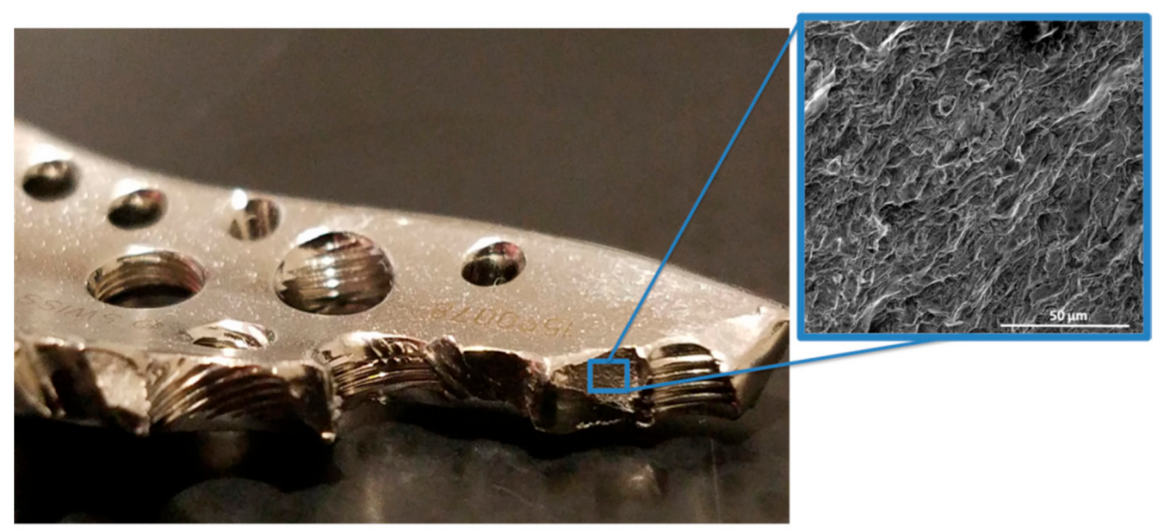

Figure A1. The quasi-cleavages, which are characteristics of fatigue failure (SEM).

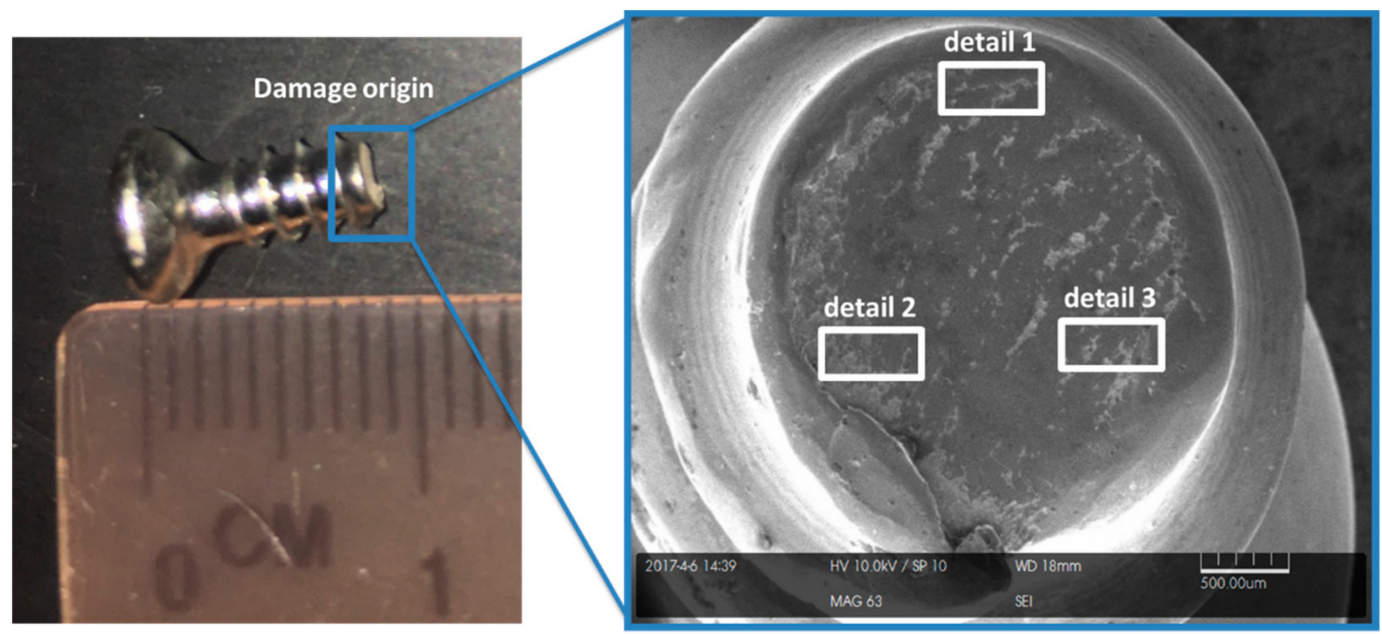

Figure A2. Topographical SEM image of the CS1 at the fracture surface showing the damage origin and the details of interest at the fracture surface.

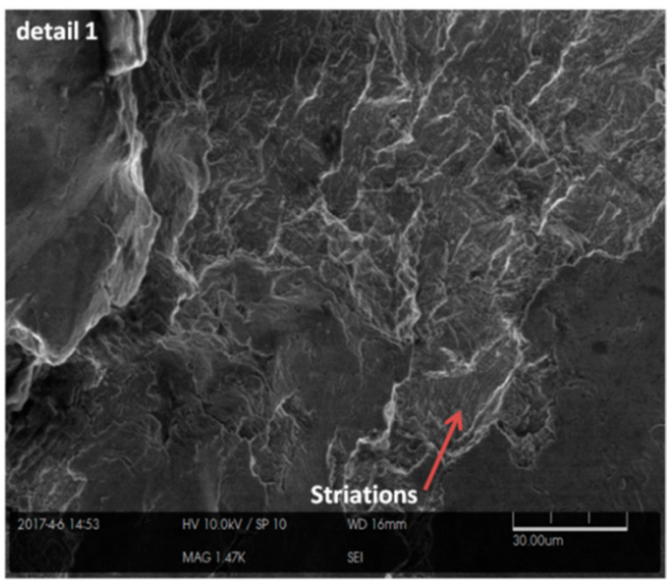

Figure A3. Topographical SEM image of the CS1 showing striations. 

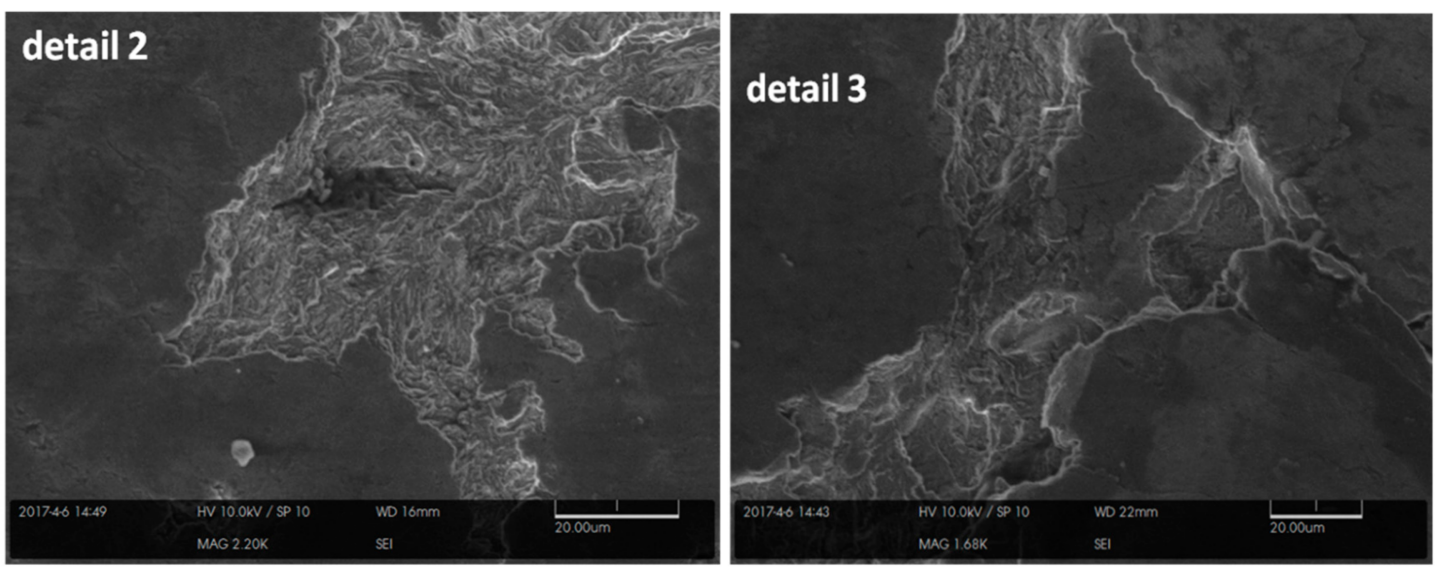

Figure A4. Topographical SEM image of the CS1 showing a microcrack at detail 2 (left). Detail 3 (right) showing striations with a severely rubbed surface.

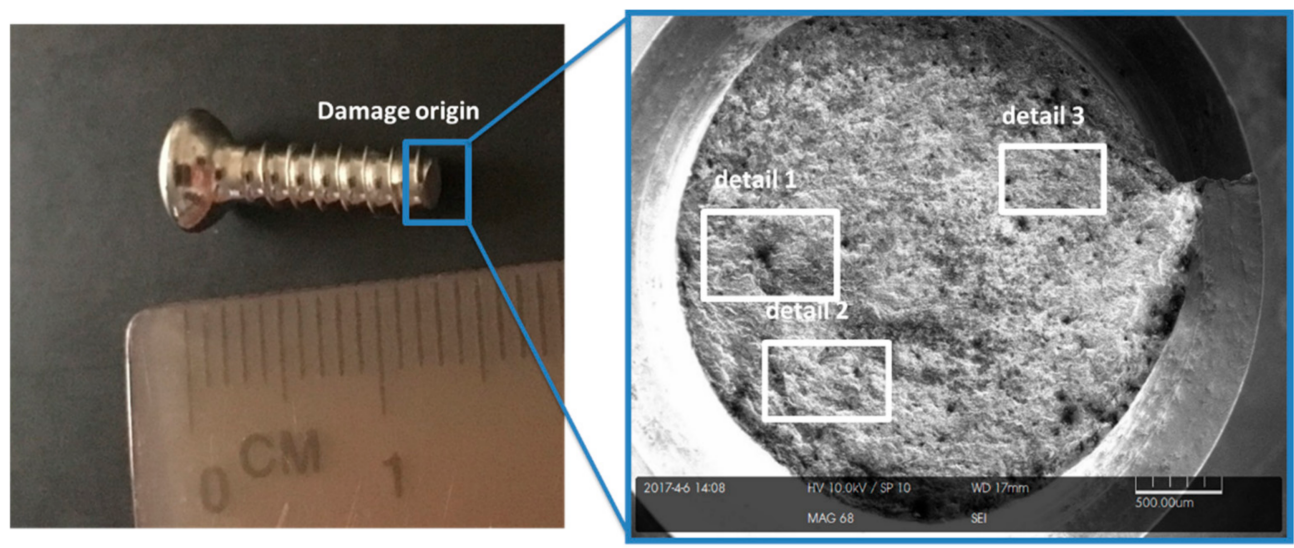

Figure A5. Topographical SEM image of the CS4 showing the details of interest at the fracture surface.

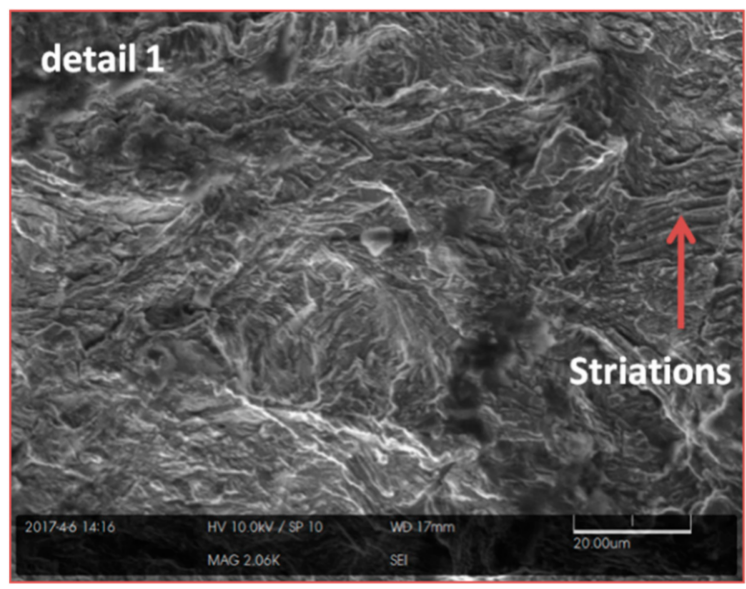

Figure A6. Topographical SEM image of the CS4 showing striations. 


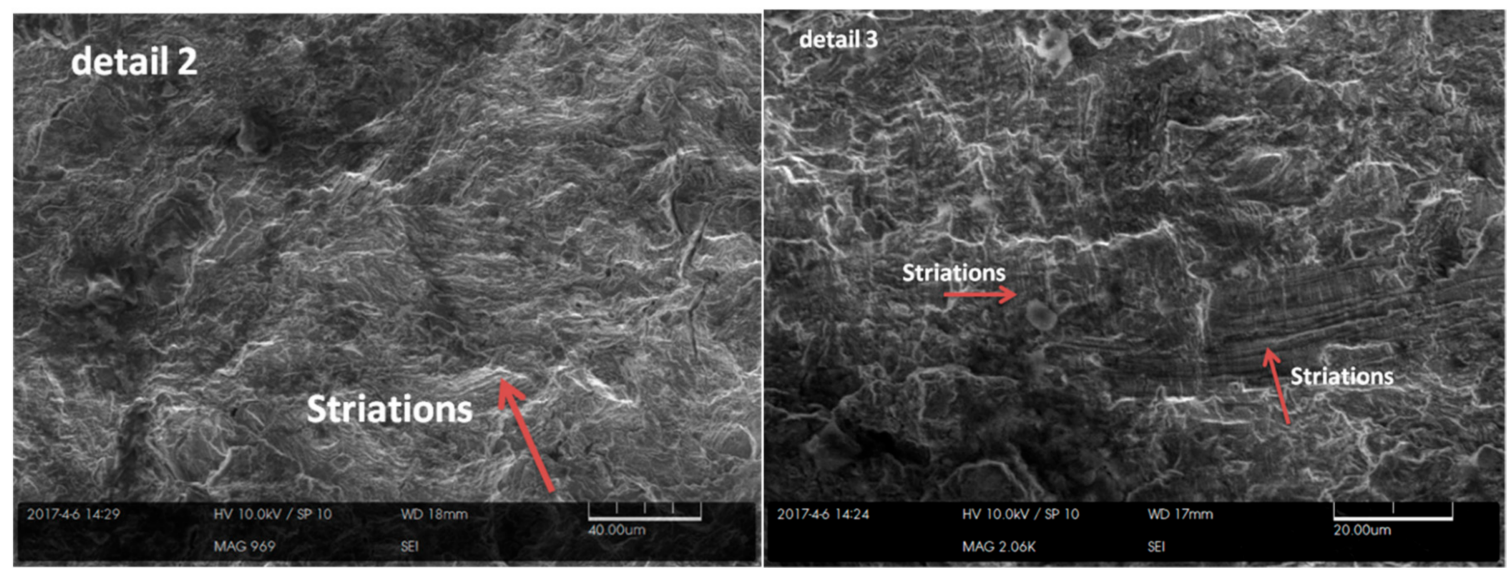

Figure A7. Topographical SEM image of the CS4 showing detail 1 (left). Detail 2 (right) showing striations.

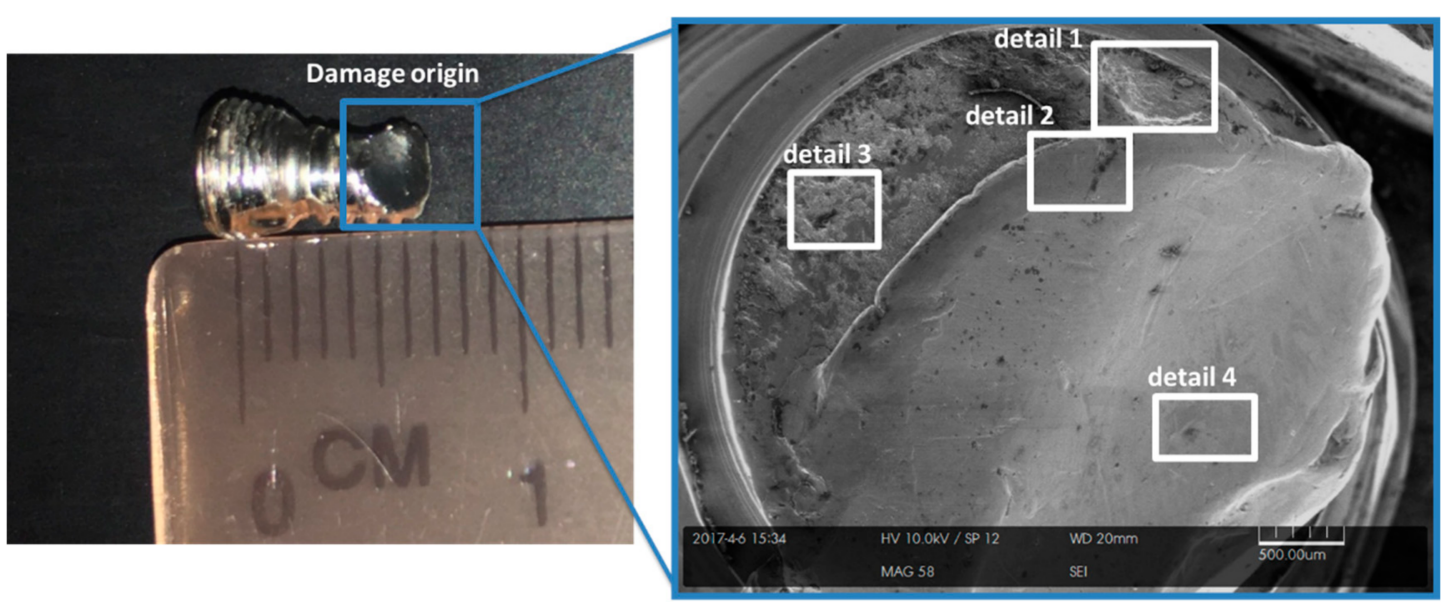

Figure A8. Topographical SEM image of the locking screw (LC) showing the damage origin and the details of interest.
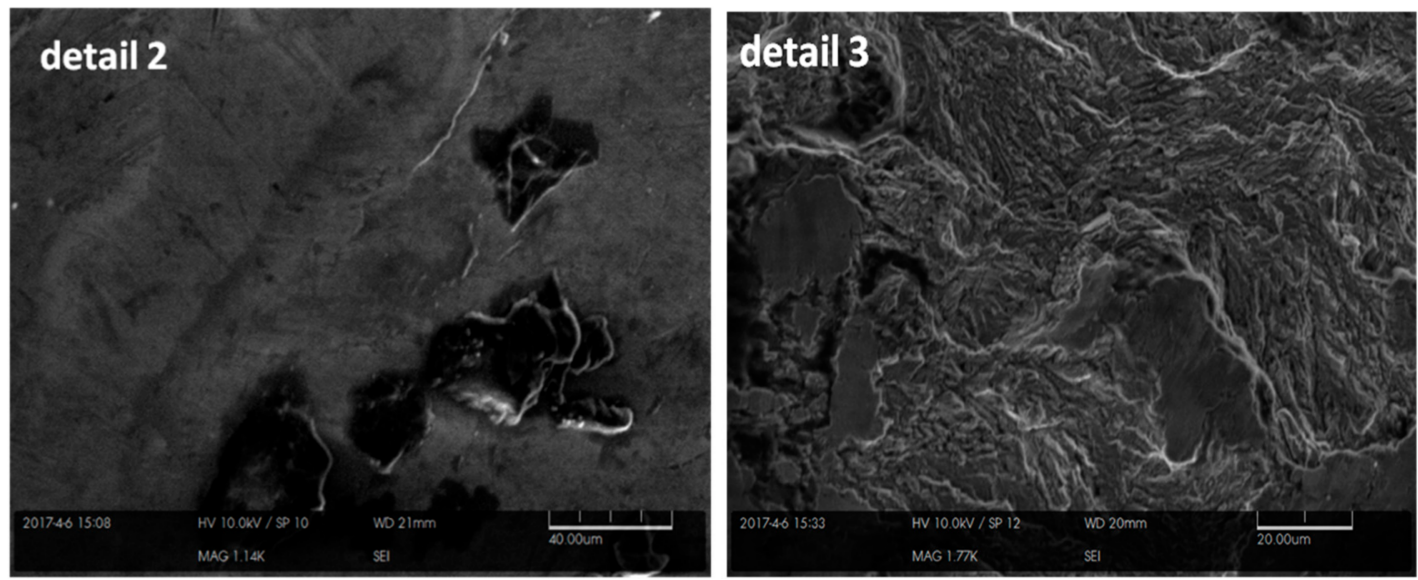

Figure A9. Topographical SEM image of the locking screw (LC) showing highly mechanically rubbed surfaces (left) with some striations on detail 3 (right). 


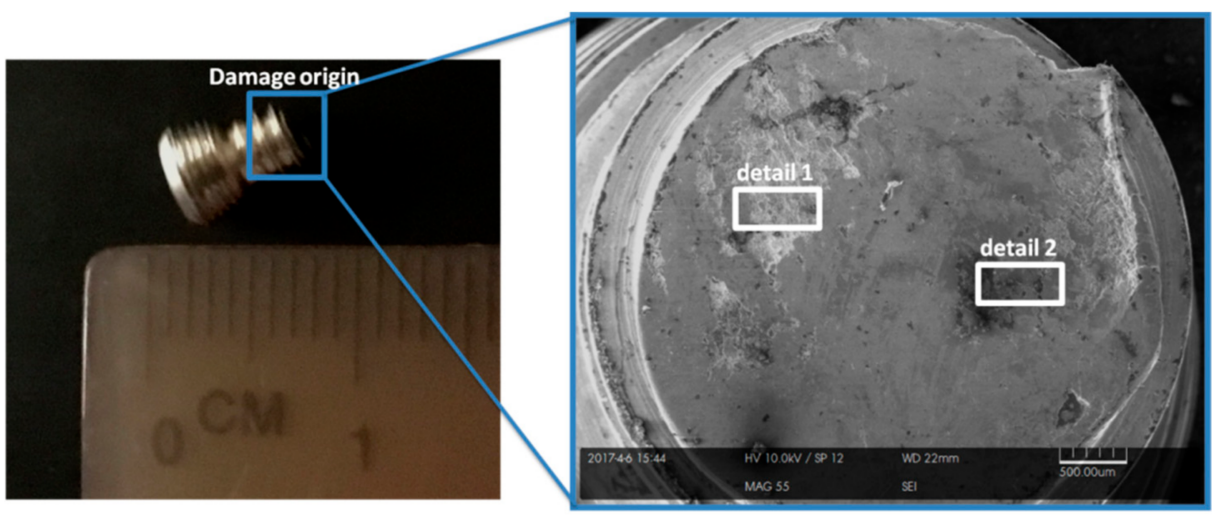

Figure A10. Topographical SEM image of the locking screw (LE) at the fracture surface showing the damage origin and the details of interest.
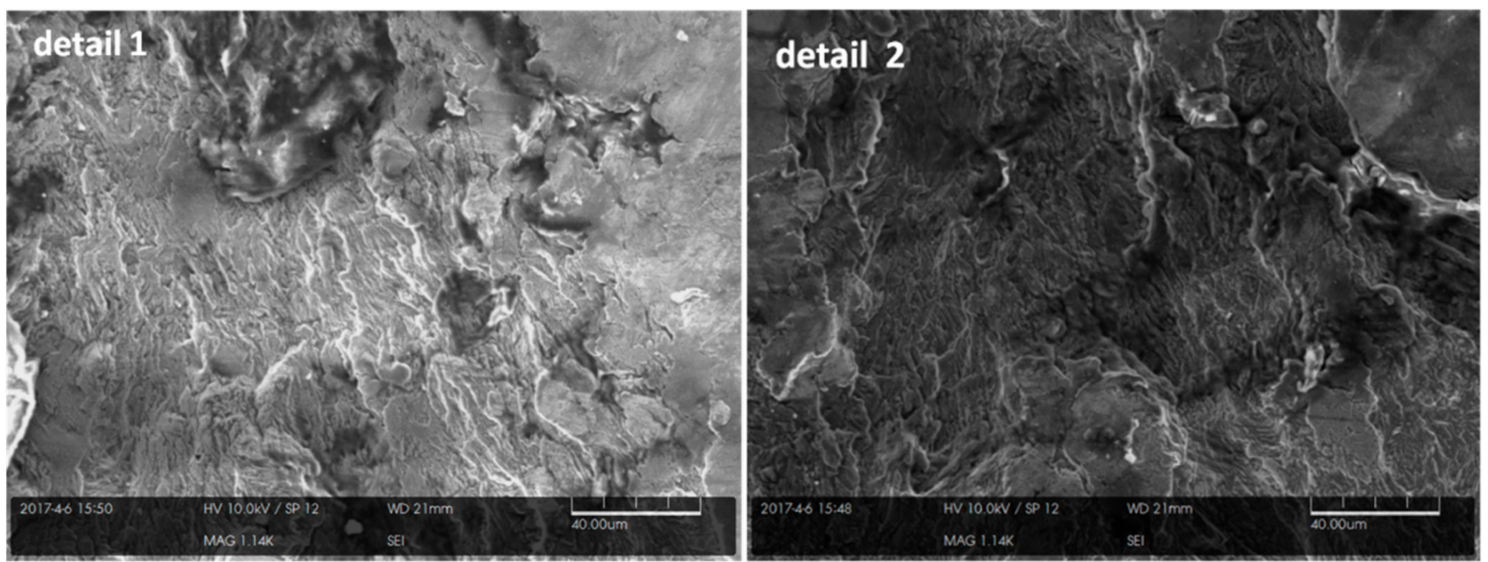

Figure A11. Topographical SEM image of the locking screw (LE) showing detail 1 (left). Detail 2 (right) showing some striations.

\section{References}

1. Ahmad, J.; Pour, A.E.; Raikin, S.M. The modified use of a proximal humeral locking plate for tibiotalocalcaneal arthrodesis. Foot Ankle Int. 2007, 28, 977-983. [CrossRef] [PubMed]

2. Mendicino, R.W.; Catanzariti, A.R.; Saltrick, K.R.; Dombek, M.F.; Tullis, B.L.; Statler, T.K.; Johnson, B.M. Tibiotalocalcaneal arthrodesis with retrograde intramedullary nailing. J. Foot Ankle Surg. 2004, 43, 82-86. [CrossRef] [PubMed]

3. Fox, I.M.; Shapero, C.; Kennedy, A. Tibiotalocalcaneal arthrodesis with intramedullary interlocking nail fixation. Clin. Podiatr. Med. Surg. 2000, 17, 19-31. [PubMed]

4. Shearman, A.D.; Eleftheriou, K.I.; Patel, A.; Pradhan, R.; Rosenfeld, P.F. Use of a proximal humeral locking plate for complex ankle and Hindfoot fusion. J. Foot Ankle Surg. 2016, 55, 612-618. [CrossRef] [PubMed]

5. Berend, M.E.; Glisson, R.R.; Nunley, J.A. A biomechanical comparison of intramedullary nail and crossed lag screw fixation for tibiotalocalcaneal arthrodesis. Foot Ankle Int. 1997, 18, 639-643. [CrossRef] [PubMed]

6. Chiodo, C.P.; Acevedo, J.I.; Sammarco, V.J.; Parks, B.G.; Boucher, H.R.; Myerson, M.S.; Schon, L.C. Intramedullary rod fixation compared with blade-plate-and-screw fixation for tibiotalocalcaneal arthrodesis: A biomechanical investigation. J. Bone Joint Surg. Am. 2003, 85, 2425-2428. [CrossRef] [PubMed]

7. Goswami, T.; Patel, V.; Dalstrom, D.J.; Prayson, M.J. Mechanical evaluation of fourth-generation composite femur hybrid locking plate constructs. J. Mater. Sci. Mater. Med. 2011, 22, 2139. [CrossRef] [PubMed]

8. Perren, S.M. Technical and biomechanical aspects of screws used in bone surgery. Int. J. Orthop. Trauma 1992, 2, 31-48. 
9. Asnis, S.E.; Kyle, R.F. (Eds.) Cannulated Screw Fixation: Principles and Operative Techniques; Springer Science \& Business Media: New York, NY, USA, 2012.

10. Patel, V. Biomechanical Evaluation of Locked and Non-Locked Constructs under Axial and Torsion Loading. (Electronic Thesis or Dissertation). 2008. Available online: https:/ / etd.ohiolink.edu/ (accessed on 14 April 2018).

11. Gautier, E.; Sommer, C. Guidelines for the clinical application of the LCP. Injury 2003, 34, B63-B76. [CrossRef] [PubMed]

12. Hsu, C.C.; Wang, J.L.; Hou, S.M.; Chao, C.K.; Lin, J. Pushout strength of tibial locking screws: Development of finite element models. J. Chin. Inst. Eng. 2003, 26, 817-823. [CrossRef]

13. Hughes, A.N.; Jordan, B.A. The mechanical properties of surgical bone screws and some aspects of insertion practice. Injury 1972, 4, 25-38. [CrossRef]

14. Chapman, J.R.; Harrington, R.M.; Lee, K.M.; Anderson, P.A.; Tencer, A.F.; Kowalski, D. Factors affecting the pullout strength of cancellous bone screws. J. Biomech. Eng. 1996, 118, 391-398. [CrossRef] [PubMed]

15. Shi, Z.; Zhang, C.; Gu, W.; Zeng, B. Ankle arthrodesis by lateral malleolus osteotomy and internal fixation with locking proximal humeral plate. Zhongguo Xiu Fu Chong Jian Wai Ke Za Zhi (Chin. J. Repar. Reconstr. Surg.) 2011, 25, 781-784.

16. Ina, J.; Vallentyne, M.; Hamandi, F.; Shugart, K.; Boin, M.; Laughlin, R.; Goswami, T. Failure Analysis of PHILOS Plate Construct Used for Pantalar Arthrodesis Paper I-Analysis of the Plate. Metals 2018, 8, 180. [CrossRef]

17. SYNTHES. 3.5 mm LCP Proximal Humerus Plate-Stainless Steel and Titanium Technique Guide. 2002. Available online: http://synthes.vo.llnwd.net/o16/LLNWMB8/US\%20Mobile/Synthes\%20North\% 20America/Product\%20Support\%20Materials/Technique\%20Guides/DSUSTRM10161133_ProxHumPl_ STG_150dpi.pdf (accessed on 7 February 2017).

18. Atlas Specialty Metals. Stainless Steel—Grade 316 L_Properties, Fabrication and Applications (UNS S31603). 2004. Available online: http:/ / www.azom.com/article.aspx?ArticleID=2382\# (accessed on 7 February 2017).

19. Azevedo, C.R.F. Failure analysis of a commercially pure titanium plate for osteosynthesis. Eng. Fail. Anal. 2002, 10, 153-164. [CrossRef]

20. Kanchanomai, C.; Phiphobmongkol, V.; Muanjan, P. Fatigue failure of an orthopedic implant-A locking compression plate. Eng. Fail. Anal. 2008, 15, 521-530. [CrossRef]

21. Amalraju, D.; Dawood, A.S. Mechanical strength evaluation analysis of stainless steel and titanium locking plate for femur bone fracture. IRACST Eng. Sci. Technol. Int. J. 2012, 2, 2250-3498.

22. ASTM. Annual Book of ASTM Standards; Construction; Soil and Rock (I); ASTM: West Conshohocken, PA, USA, 2005; Volume 13.01.

23. Allen, R.F. Standard specification for wrought 18 chromium-14 nickle-2.5 molybdenum stainless steel bar and wire for surgical implants (F138). In Annual Book of ASTM Standards, Medical Devices and Services; ASTM: West Conshohocken, PA, USA, 1998.

24. SYNTHES. Screws, Drill Bits, Taps and Guide Wires. 2002. Available online: http://www. cambridgeorthopaedics.com/easytrauma/classification/commonfiles/Synthes\%20screws.pdf (accessed on 7 February 2017).

25. Hamandi, F.; Goswami, T. Macrodamage Accumulation Model for a Human Femur. Appl. Bionics Biomech. 2017, 2017, 4539178. [CrossRef] [PubMed]

26. Michael, J.M.; Golshani, A.; Gargac, S.; Goswami, T. Biomechanics of the ankle joint and clinical outcomes of total ankle replacement. J. Mech. Behave. Biomed. Mater. 2008, 1, 276-294. [CrossRef] [PubMed]

27. Perren, S.M. Evolution of the internal fixation of long bone fractures: The scientific basis of biological internal fixation: Choosing a new balance between stability and biology. Bone Jt. J. 2002, 84, 1093-1110. [CrossRef]

28. Goswami, T.; Gundapaneni, D.; Slocum, M.; Paul, P.; Christof, S. Failure investigation of a tibiotalocalcaneal arthrodesis system. Eng. Fail. Anal. 2016, 59, 588-604. [CrossRef]

29. Egol, K.A.; Kubiak, E.N.; Fulkerson, E.; Kummer, F.J.; Koval, K.J. Biomechanics of locked plates and screws. J. Orthop. Trauma 2004, 18, 488-493. [CrossRef] [PubMed]

30. Borgeaud, M.; Cordey, J.; Leyvraz, P.F.; Perren, S.M. Mechanical analysis of the bone to plate interface of the LC-DCP and of the PC-FIX on human femora. Injury 2000, 31, C29-C36. [CrossRef]

31. Narayan, R.; Burt, V.; Lampman, S.; Marken, K.; Marquard, E.; Riley, B. ASM Handbook. In Materials for Medical Devices; ASM International: Materials Park, OH, USA, 2012; Volume 23. 
32. Majid, K.; Crowder, T.; Baker, E.; Baker, K.; Koueiter, D.; Shields, E.; Herkowitz, H.N. Analysis of in vivo corrosion of $316 \mathrm{~L}$ stainless steel posterior thoracolumbar plate systems: A retrieval study. Clin. Spine Surg. 2011, 24, 500-505.

33. Sivakumar, M.; Mudali, U.K.; Rajeswari, S. Investigation of failures in stainless steel orthopaedic implant devices: Fatigue failure due to improper fixation of a compression bone plate. J. Mater. Sci. Lett. 1994, 13, 142-145. [CrossRef]

34. Thapa, N.; Prayson, M.; Goswami, T. A failure study of a locking compression plate implant. Case Stud. Eng. Fail. Anal. 2015, 3, 68-72. [CrossRef]

(c)

(C) 2018 by the authors. Licensee MDPI, Basel, Switzerland. This article is an open access article distributed under the terms and conditions of the Creative Commons Attribution (CC BY) license (http://creativecommons.org/licenses/by/4.0/). 